\title{
Inhibitory effect of Zanthoxylum bungeanum seed oil on ovalbumin-induced lung inflammation in a murine model of asthma
}

\author{
JUN-QIN WANG ${ }^{1}$, XIAO-WEI LI ${ }^{2}$, MINGYI LIU ${ }^{1}$, SHENG-CHUN WANG ${ }^{1}$ and ZENG-FA CAO ${ }^{2}$ \\ ${ }^{1}$ Department of Pharmacy, Xijing Hospital, The Fourth Military Medical University, Xi'an, Shaanxi 710032; \\ ${ }^{2}$ Xin Run Pharmaceutical Limited Company, Xi'an, Shaanxi 710075, P.R. China
}

Received March 23, 2015; Accepted February 1, 2016

DOI: $10.3892 / \mathrm{mmr} .2016 .5050$

\begin{abstract}
The present study aimed to investigate the therapeutic efficacy of Zanthoxylum bungeanum seed oil (Z. seed oil) to alleviate airway inflammation in asthmatic mice. The asthmatic mice were treated with vehicle, ovalbumin (OVA), or OVA + Z. seed oil $(2 \mathrm{~g} / \mathrm{kg})$ for between $24 \mathrm{~h}$ and 14 days. Following treatment, inflammatory cell infiltration and pulmonary tissue damage were assessed by hematoxylin and eosin staining, and immunohistochemistry. The expression levels of pro-inflammatory cytokines, chemokines, adhesion molecules and mitogen activated protein kinase signaling proteins were measured by enzyme-linked immunosorbent assays, reverse transcription quantitative-polymerase chain reaction and western blot analysis. In asthmatic mice, administration of Z. seed oil attenuated lung tissue injury and airway remodeling, and inhibited the infiltration of leukocytes and eosinophils into the airway by reducing the expression levels of inflammatory cytokines and chemokines compared with OVA-treated mice
\end{abstract}

Correspondence to: Dr Sheng-Chun Wang, Department of Pharmacy, Xijing Hospital, The Fourth Military Medical University, 127 Changle West Road, Xincheng, Xi'an, Shaanxi 710032, P.R. China

E-mail: wangshen@fmmu.edu.cn

Abbreviations: Z. seed oil, Zanthoxylum bungeanum seed oil; OVA, ovalbumin; BALF, bronchoalveolar lavage fluid; MCP-1, monocyte chemoattractant protein-1; IL, interleukin; IFN $\gamma$, interferon $\gamma$; LTC4S, leukotriene C4 synthase; CCR-3, chemokine (C-C motif) receptor-3; VCAM-1, vascular cell adhesion molecule-1; ICAM-1, intercellular adhesion molecule-1; TNF- $\alpha / \mathrm{R}$, tumor necrosis factor- $\alpha /$ receptor; MAPK, mitogen-activated protein kinase; ERK, extracellular signal-regulated kinase; JNK, c-jun N-terminal kinase; PCNA, proliferating cell nuclear antigen; TLR, toll-like receptor; ATF-2, activating transcription factor-2; IRAK, interleukin-1 receptor-associated kinase

Key words: Zanthoxylum bungeanum seed oil, asthma, inflammation, cytokines, chemokines
$(\mathrm{P}<0.05)$. Z. seed oil also reduced the levels of inflammatory chemokine and adhesion molecules via downregulation of extracellular signal-regulated kinase and activation of c-JUN $\mathrm{N}$-terminal kinase in the $\mathrm{Z}$. seed-treated mice compared with OVA-treated mice $(\mathrm{P}<0.05)$. Thus, data from the present study indicates that $\mathrm{Z}$. seed oil can suppress pulmonary inflammation and tissue injury during asthma, and suggests that it may be used to effectively treat allergen-induced asthma.

\section{Introduction}

Bronchial asthma is a complex chronic inflammatory disease of the airways characterized by repeated episodes of airway hyperresponsiveness (AHR) (1) and an allergic inflammatory response. This process involves the infiltration of inflammatory cells, including mast cells, eosinophils, neutrophils and lymphocytes, into the pulmonary tissue $(2,3)$.

A number of epidemiological studies have investigated the incidence of asthma in adults, estimated incidence rates are varied, ranging between $1 / 1000$ and $7 / 1000$ person-years $(4,5)$. An overall incidence rate of $2 / 1000$ person-years in the 20-50 years age group has been determined in previous studies with a prospective design $(6,7)$. Therapy with medium to high doses of inhaled corticosteroids are currently generally effective in achieving symptom relief (8).

Mitogen-activated protein kinases (MAPKs) are intracellular signal transduction molecules implicated in airway inflammation and AHR (9). There are three major groups of MAPKs in mammalian cells, including extracellular signal-regulated kinase 1/2 (ERK1/2), p38 MAPK and c-JUN $\mathrm{N}$-terminal kinase (JNK) (10). ERK1/2 is significantly increased in lung tissue in response to allergens (11), and promotes the production of inflammatory cytokines and chemokines (12). In addition, ERK1/2 contributes to goblet cell metaplasia (13), T-helper 2 ( Th2) cell differentiation, proliferation of mature B cells and the migration of eosinophils (14).

Zanthoxylum bungeanum Maxim, known in China as Hua Jiao, is a member of the Rutaceae family. The fruits of Zanthoxylum are used as a spice in Chinese cuisine, and as a traditional medicine for the treatment of stomachache, toothache, abdominal pain, ascariasis and diarrhea (15). Previous studies have supported the therapeutic properties of 
Zanthoxylum, and it was indicated that the chloroform-soluble extract of Zanthoxylum is able to inhibit hepatitis B virus DNA replication (16-19). Furthermore, Z. bungeanum seed oil (Z. seed oil) demonstrated a significant antioxidant activity (20). However, the therapeutic potential of $Z$. seed oil remains undefined, particularly in inflammatory diseases, such as asthma. In the present study, the effect of Z. seed oil was investigated in an ovalbumin (OVA)-induced asthmatic murine model, and the data suggested that $\mathrm{Z}$. seed oil may serve as a potential anti-inflammatory agent for asthmatic patients.

\section{Materials and methods}

Preparation of Z seed oil. Whole Z. bungeanum seeds were collected from Hangcheng (Shaanxi, China) in September 2008 and dried; the oil was then extracted by squeezing $100 \mathrm{~kg}$ of broken seeds using a multifunctional oil press (Gongyi Xiaoyi Jinwang Machinery Factory, Gongyi, China). Voucher specimens of the seeds and oil extract were deposited at the Xin Run Pharmaceutical Company (Xi'an, China). The crude oil was purified using a silica gel column (Qingdao Yonghai Silica Gel Co., Ltd., Qingdao, China) and activated carbon chromatography. The ratio of crude oil, silica gel and activated carbon (Lv Bao Shi Industry and Trade Co., Ltd., Xi'an, China) in the glass column was 1:5:0.5. The purified oil (one of 16 fragments) was eluted from the column with petroleum ether (Li'an-Long Bohua Medical Chemical Co., Ltd., Shaanxi, China) and ethanol (Li'an-Long Bohua Medical Chemical Co., Ltd.) at a ratio of 8:2 at room temperature. Eluates were then concentrated under reduced pressure $(0.6 \mathrm{kPa})$.

Animals and treatments. All experimental protocols were approved by the Institutional Ethical Committee for Animal Experimentation of The Fourth Military Medical University (Xi'an, China). Male BALB/c mice (Experimental Animal Center, The Fourth Military Medical University; age, 6-8 weeks; weight, $22 \pm 2 \mathrm{~g}, \mathrm{n}=240$ ) were fed with a standard diet and a constant supply of tap water. In addition, mice were housed in a 12 -h light/dark cycle at room temperature $\left(23 \pm 3^{\circ} \mathrm{C}\right)$ with $40-60 \%$ relative humidity levels. The mice were divided into three groups of 80 (which was further divided into 5 time points, $n=16$ ): Vehicle control (non-asthmatic), OVA-treated and OVA + Z. seed oil-treated. The vehicle control group was administered with $200 \mu 1$ saline (Shandong Jiejing Pharmaceutical Co., Ltd., Rizhou, China) only. To induce allergic asthma in the OVA-treated and OVA $+\mathrm{Z}$. seed-treated groups, mice were administered with $20 \mathrm{mg}$ OVA (Sigma-Aldrich, St. Louis MO, USA) emulsified with $40 \mathrm{mg}$ aluminum hydroxide (Shanghai Huashi Pharmaceutical Co., Ltd., Shanghai, China) in $200 \mu 10.9 \%$ saline intraperitoneally (i.p.). Eight days after the initial sensitization, mice were administered $5 \mathrm{mg}$ OVA emulsified with $10 \mathrm{mg}$ aluminum hydroxide in $200 \mu \mathrm{l}$ saline (i.p.). On day 14, the OVA-treated mice were administered $50 \mu \mathrm{l}$ saline (containing $20 \mu \mathrm{g} / 50 \mu \mathrm{l}$ OVA) via intranasal inhalation for 24 and $48 \mathrm{~h}$, and 3, 7 and 14 days. Mice in the $\mathrm{Z}$. seed oil-treated group were administered $50 \mu \mathrm{l}$ saline (containing $20 \mu \mathrm{g} / 50 \mu \mathrm{l}$ OVA) via intranasal inhalation, after $30 \mathrm{~min} 2 \mathrm{~g} / \mathrm{kg} \mathrm{Z}$. seed oil was administered orally, once per day for 24 and $48 \mathrm{~h}$ and 3, 7 and 14 days, while mice in the vehicle and OVA-treated groups were administered placebo edible oil (Yihai Kerry Foodstuffs Marketing Co., Ltd., Shenzhen, China) once per day.

Following treatment, six mice from each group were selected for bronchoalveolar lavage fluid (BALF) collection. Briefly, $60 \mathrm{mg} / \mathrm{kg}$ sodium pentobarbital (Guangzhou Chemical Reagent Factory, Guangzhou, China) was administered i.p. and a tracheal intubation tube was inserted. Lungs were flushed three times with $0.5 \mathrm{ml}$ sterilized saline to recover $\sim 1.2 \mathrm{ml}$ BALF. These mice were then sacrificed by cervical dislocation. In addition, for each time point, eight mice per group were sacrificed by cervical dislocation and their lungs were collected. Four pairs of lungs per group were fixed in $4 \%$ buffered paraformaldehyde solution (Tianjin Baishi Chemical Co., Ltd., Tianjin, China) and embedded in paraffin (Leica Microsystems GmbH, Wetzlar, Germany) for histological examination. The remaining four pairs of lungs were washed with ice-cold saline, dehydrated with filter paper and stored at $-80^{\circ} \mathrm{C}$ for further analysis.

Measurement of interleukin-4 (IL-4), IL-5, interferon $\gamma$ $(I F N \gamma)$, leukocytes and eosinophils levels in BALF. The collected BALF was centrifuged for $5 \mathrm{~min}$ at $380 \mathrm{x} \mathrm{g}$ and $4^{\circ} \mathrm{C}$ to separate the cells from the supernatant. The supernatant was stored at $-80^{\circ} \mathrm{C}$ to be used for the measurement of cytokines. As indicators of inflammation, the concentrations of IL-4, IL-5 and IFN- $\gamma$ were measured in the BALF supernatants using enzyme linked immunosorbent assays, according to the manufacturer's protocol (Shanghai Bio-Tech Co., Ltd., Shanghai, China). The BALF cell pellet was resuspended in $100 \mu \mathrm{l}$ Wright staining solution (Zhuhai Beisuo Biotechnology Co., Ltd., Zhuhai, China) and total leukocytes were measured with a Neubauer hemocytometer (Jiangyin Medical Devices Co., Ltd., Jiangyin, China). To quantify the eosinophil and neutrophil cell populations, $50 \mu \mathrm{l}$ of the resuspended cells were adhered onto a glass slide using an Invitrogen Cytospin centrifuge (Thermo Fisher Scientific, Inc., Waltham, MA, USA) at $400 \mathrm{x}$ g for $4 \mathrm{~min}$. Slides were stained with Giemsa stain (Zhuhai Beisuo Biotechnology Co., Ltd.) following standard protocols. Eosinophils were identified by a rose-red cytoplasm and neutrophils by a light pink cytoplasm. A total of 500 cells were counted under a microscope (DM LB; Leica Microsystems GmbH; $\mathrm{x} 1,000$ magnification) and the percentage of eosinophils was calculated.

Histological analysis of lung sections and lung inflammation grading. The paraffin-embedded fixed lung samples were cut into $4-\mu \mathrm{m}$ tissue sections. For the examination of bronchial inflammation, lung tissue sections were stained with hematoxylin and eosin (H\&E; Zhuhai DL Biotech Co., Ltd., Zhuhai, Guangdong, China) visualized with a DM LB microscope and scored using established criteria (21) in a blinded manner by two pathologists averaging their judgments for the categorization. Inflammatory cell infiltration was graded into four categories: Grade 0, normal lung structure; Grade I, infiltration of a small number of diffuse inflammatory cells; Grade II, a 1-cell thick ring of inflammatory cells; Grade III, a 2-4 cell thick ring of inflammatory cells; Grade IV, a ring of inflammatory cells $>4$ cells deep. 


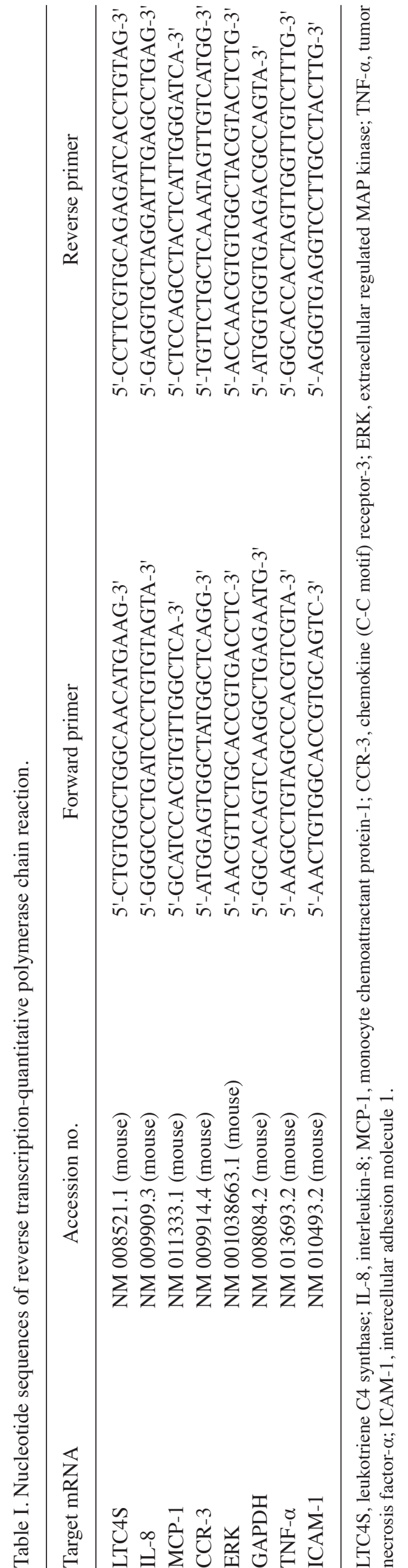

Immunohistochemistry. Lung tissue sections were deparaffinized with xylene (Li'an-Long Bohua Medical Chemical Co., Ltd.) and washed in serial dilutions of ethanol for immunohistochemical staining analysis. Endogenous peroxidase activity was blocked with $3 \%$ hydrogen peroxide in methanol (Li'an-Long Bohua Medical Chemical Co., Ltd.) for $5 \mathrm{~min}$, and non-specific binding was blocked with $1 \%$ bovine serum albumin (Chembase Bio; Beijing, China) in phosphate-buffered saline (PBS; EUROIMMUN AG, Luebeck, Germany) for $1 \mathrm{~h}$. Sections were incubated with rabbit polyclonal proliferating cell nuclear antigen (PCNA) primary antibody (1:600; BIOSS, Beijing, China; cat. no. bS-0941R) overnight at $4^{\circ} \mathrm{C}$. Following three PBS washes $(2 \mathrm{ml})$, slides were incubated with horseradish peroxidase-conjugated AffiniPure goat anti-mouse $\operatorname{IgG}(\mathrm{H}+\mathrm{L})$ for $20 \mathrm{~min}$ (cat. no. ZB-2305) for $20 \mathrm{~min}$. Immunoreactivity was visualized with a 3,3'-diaminobenzidine substrate (Zymed Laboratories; Thermo Fisher Scientific, Inc.), the slides were counterstained with $\mathrm{H} \& \mathrm{E}$, and then mounted using resin adhesive (Leica Microsystems $\mathrm{GmbH}$ ). All stained tissue sections were analyzed with bright-field microscopy using a DM LB microscope.

Reverse transcription-quantitative polymerase chain reaction (RT-qPCR). For RT-qPCR analysis, frozen tissue samples were homogenized in TRIzol (Takara Bio, Inc., Otsu, Japan) using $1 \mathrm{ml}$ TRIzol per $50 \mathrm{mg}$ of lung tissue, and total RNA was extracted using RNAiso Plus kit (Takara Bio, Inc.) according to the manufacturer's protocol. RNA concentration was measured using a spectrophotometer (DU-800; Beckman Coulter, Inc., Brea, CA, USA). RT-qPCR was conducted using the PrimeScript ${ }^{\mathrm{TM}}$ RT Master mix kit (Takara Bio, Inc.) according to the manufacturer's protocols. Probes were synthesized by Takara Bio, Inc.

Following RT, the cDNA products were amplified in a Bio-Rad iQ ${ }^{\mathrm{TM}} 5$ Real Time PCR detection system (Bio-Rad Laboratories, Inc., Hercules, CA, USA) with reaction conditions, as follows: $95^{\circ} \mathrm{C}$ for $30 \mathrm{sec}$, followed by 40 cycles at $95^{\circ} \mathrm{C}$ for $10 \mathrm{sec}$ and $60^{\circ} \mathrm{C}$ for $20 \mathrm{sec}$ ). Each sample had a final volume of $20 \mu \mathrm{l}$ containing $80 \mathrm{ng}$ cDNA, $0.8 \mu \mathrm{l}$ forward and reverse primers, $10 \mu 12 \mathrm{X} \mathrm{SYBR}{ }^{\circledR}$ Premix Ex Taq (Takara

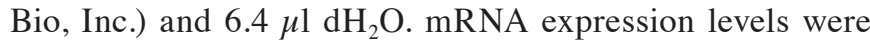
determined using a Bio-Rad iQ ${ }^{\mathrm{TM}} 5$ Real Time PCR detection system (Bio-Rad Laboratories, Inc.) using the specific primers indicated in Table I. Following amplification, melting curve analysis was performed to assess the specificity of the amplified PCR products. qPCR products were quantified by the quantification cycle at which specific fluorescence became detectable (22). The mRNA levels of each gene were normalized to those of the housekeeping gene GAPDH.

Protein extraction and western blotting. Pulmonary tissue was washed with ice-cold PBS, lysed with radioimmunoprecipitation assay buffer (Beyotime Institute of Biotechnology, Haimen, China; 50 mM Tris-HCl, pH 7.2; $150 \mathrm{mM} \mathrm{NaCl} ; 1 \%$ NP 40; 0.1\% SDS; 1 mM EDTA; $1 \mathrm{mM}$ phenylmethanesulfonyl fluoride) and then homogenized in ice-cold water for 2-3 min. The lung homogenate samples were incubated for $30 \mathrm{~min}$ at $4^{\circ} \mathrm{C}$ and shaken by hand every $10 \mathrm{~min}$. Samples were then centrifuged at $24,000 \mathrm{x}$ g for $10 \mathrm{~min}$ at $4^{\circ} \mathrm{C}$ and the supernatants were collected. Total protein concentration was 
determined using the BCA protein assay (Beyotime Institute of Biotechnology) and the samples were denatured in 5X loading buffer by incubation at $100^{\circ} \mathrm{C}$ for $10 \mathrm{~min}$. Equal quantities of protein from each treatment group were separated on $10 \%$ SDS-polyacrylamide gels run at $120 \mathrm{~V}$ for $60 \mathrm{~min}$ and then electro-transferred to a polyvinylidene difluoride membranes (EMD Millipore, Billerica, MA, USA). Membranes were incubated with primary antibodies, as follows rabbit polyclonal anti-Ras (1:1,000; Cell Signaling Technology, Inc., Danvers, MA, USA; cat. no. 3965), rabbit polyclonal anti-ERK1/2 (1:1,000; Santa Cruz Biotechnology, Inc.; cat. no. sc-94), rabbit polyclonal anti-phosphorylated (p)-ERK1/2 (1:600; Santa Cruz Biotechnology, Inc.; sc-7383), rabbit polyclonal anti-p38 MAPK (1:800; Santa Cruz Biotechnology, Inc.; sc-7149), rabbit polyclonal anti-p-p38 MAPK (1:1,000; Cell Signaling Technology, Inc.; cat. no. 9211), rabbit polyclonal anti-JNK (1:800; Santa Cruz Biotechnology, Inc.; sc-572), rabbit polyclonal anti-nuclear factor- $\kappa \mathrm{B}-\mathrm{p} 65$ (NF- $\kappa \mathrm{B}-\mathrm{p} 65$; 1:1,000; Santa Cruz Biotechnology, Inc.; cat. no. sc-372), rabbit polyclonal anti-c-fos (1:1,000; Santa Cruz Biotechnology, Inc.; cat. no. sc-52), rabbit polyclonal anti-c-JUN (1:600; Santa Cruz Biotechnology, Inc.; cat. no. sc-1694), rabbit polyclonal $\beta$-actin (1:600; Wuhan Boster Biological Technology, Ltd., Wuhan, China; cat.no.MK1656), mouse monoclonal anti-p-JNK (1:600; Cell Signaling Technology, Inc.; cat.no. sc-6254), mouse monoclonal anti-p-activating transcription factor-2 (ATF-2; 1:600; Santa Cruz Biotechnology, Inc.; cat. no. sc-8398), rabbit monoclonal anti-p-NF-кB-p65 (1:1,000; Cell Signaling Technology, Inc.; cat. no. 3033), rabbit polyclonal intercellular adhesion molecule 1 (ICAM-1; 1:600; BIOSS; cat. no. bS-0608R), rabbit polyclonal anti-tumor necrosis factor- $\alpha$ (TNF- $\alpha$; $1: 600$; BIOSS; cat. no. bS-00789), rabbit polyclonal anti-CD14 (1:600; Wuhan Boster Biological Technology, Ltd.; cat. no. BA0719-2), rabbit polyclonal anti-TNF-receptor (TNF-R; 1:600; BIOSS; cat. no. bS-2941R), rabbit polyclonal anti-toll-like receptor (TLR)2 (1:600; BIOSS; cat. no. bS-1019R) and rabbit polyclonal anti-TLR4 (1:600; BIOSS; cat. no. bS-1021R). The membranes were then incubated with AffiniPure anti-mouse (ZB-2301) or anti-rabbit (ZB-2305) horseradish peroxidase-conjugated AffiniPure IgG $(\mathrm{H}+\mathrm{L})$ secondary antibodies (ZSGB-BIO, Beijing, China). After washing with Tris-buffered saline and Tween 20, membranes were incubated with enhanced chemiluminescence substrate (Pierce Chemical Co., Dallas, TX, USA) and signals were visualized by exposure to X-ray films (Tianjin Media Imaging Materials Co., Ltd., Tianjin, China). Proteins were quantified by densitometry using Gel-Pro Analyzer Image software version 4.0 (Media Cybernetics Inc., Rockville, MD, USA). All protein levels were normalized relative to the $\beta$-actin expression.

Nuclear protein extraction. Nuclear extracts were prepared using the Nuclear and Cytoplasmic Protein Extraction kit, according to the manufacturer's protocol (Nanjing KeyGen Biotech Co., Ltd., Nanjing, China). Briefly, $100 \mathrm{mg}$ lung tissue from each group were homogenized in ice-cold PBS and incubated for $5 \mathrm{~min}$ on ice to allow large particles to settle. The supernatant was then transferred and centrifuged at $500 \mathrm{xg}$ for $3 \mathrm{~min}$. The supernatant was discarded and $100 \mu \mathrm{l}$ cold Buffer A (supplemented with protease inhibitors) was added for every $10 \mu \mathrm{l}$ of packed cells. Samples were vortexed for
$15 \mathrm{sec}$ and incubated on ice for $10-15$ min prior to addition of cold Buffer B. Samples were then vortexed and centrifuged at $16,000 \times \mathrm{g}$ at $4^{\circ} \mathrm{C}$ for $5 \mathrm{~min}$, and the supernatant containing cytoplasmic proteins was collected. Nuclear proteins were extracted by incubating the remaining pellet with cold Buffer C. Samples were incubated on ice for $40 \mathrm{~min}$, shaken by hand every $10 \mathrm{~min}$ and centrifuged at $16,000 \mathrm{x}$ g at $4^{\circ} \mathrm{C}$ for $10 \mathrm{~min}$. The supernatant containing nuclear proteins was collected, flash-frozen in liquid nitrogen and stored at $-80^{\circ} \mathrm{C}$.

Statistical analysis. The experimental results are presented as the mean \pm standard deviation. Statistical analysis was performed using the paired, nonparametric Student's t-test or one-way analysis of variance, followed by the Bonferroni correction or the Games-Howell test. SPSS software (version 17.0; SPSS, Inc., Chicago, IL, USA) was used perform all tests and a value of $\mathrm{P}<0.05$ was considered to indicate a statistically significant difference.

\section{Results}

Histological analyses of the effect of Z. seed oil in OVA-induced asthmatic mice. To investigate the therapeutic efficacy of $Z$. seed oil in the lung tissue of asthmatic mice, a well-established murine model of asthma was employed to induce asthma by OVA exposure for time periods ranging between $24 \mathrm{~h}$ and 14 days. In addition to the OVA treatment, mice were administered either placebo edible oil or Z . seed oil. Following treatment, mice were sacrificed and the lung tissue was collected for analysis by $\mathrm{H} \& \mathrm{E}$ and immunohistochemical staining (Fig. 1). Lung tissue sections from vehicle-treated mice demonstrated an inflammatory infiltration score of $0.30 \pm 0.10$ (24 h), $0.30 \pm 0.10$ (48 h), $0.43 \pm 0.11$ (72 h), 0.36 \pm 0.05 (7 days) and $0.50 \pm 0.26$ (14 days) (Fig. 1A, D and G), indicating healthy and intact lung structure without significant inflammation. By contrast, lung tissue from OVA-treated mice revealed marked infiltration of inflammatory cells (primarily eosinophils and neutrophils) into the peribronchial and perivascular connective tissues as early as $24 \mathrm{~h}$ after OVA treatment (Fig. 1B and E). The OVA-treated group had a pulmonary injury score of $2.36 \pm 0.48$ at $48 \mathrm{~h}$ (Fig. 1G), and grade II inflammation was observed, as indicated by the one-cell thick ring of infiltrated inflammatory cells in Fig. 1B. This demonstrated significant pulmonary inflammation at an early stage of asthma sensitization. Furthermore, the inflammation score was significantly higher in the OVA-treated group compared with the vehicle at all time points $(\mathrm{P}<0.05$; Fig. $1 \mathrm{G})$.

Lung inflammation and tissue damage substantially increased following $48 \mathrm{~h}$ of sustained OVA challenge. Infiltration of inflammatory markers markedly increased, and swelling on the alveolar walls, alveolar epithelial cells and a massive influx of polymorphonuclear leukocytes were observed (Fig. 1B and E). Analysis of the lung tissue at $48 \mathrm{~h}$ revealed an inflammatory cell infiltration score of $2.4 \pm 0.45$ (Fig. 1G), with class III inflammation, as indicated by the 2-4 cell thick ring of inflammatory cells (Fig. 1B). After $72 \mathrm{~h}$ of OVA challenge, inflammation was even more pronounced, with an infiltration score of $3.56 \pm 0.72$ (Fig. 1G), and grade IV inflammation, as indicated by the $>4$-cell thick ring of inflammatory cells (Fig. 1B). In addition to the phenotypes 
A

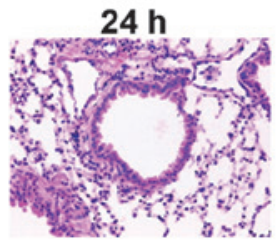

B

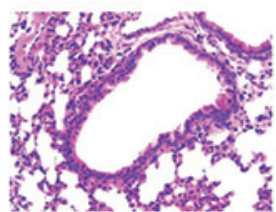

C

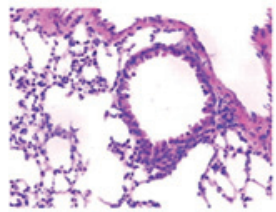

D

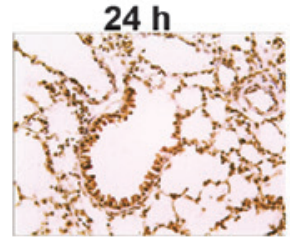

$\mathbf{E}$

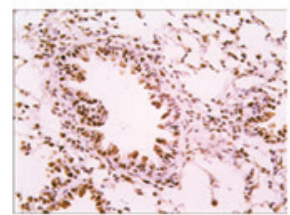

$\mathbf{F}$

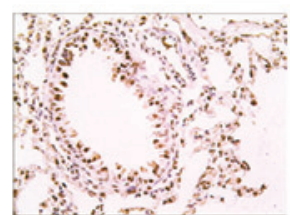

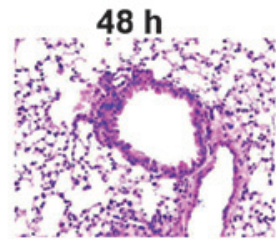
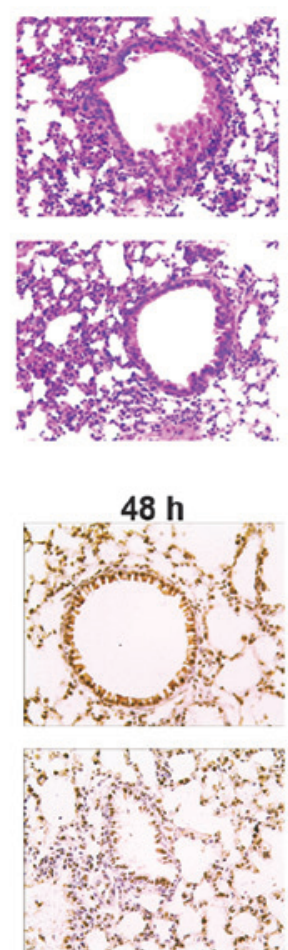

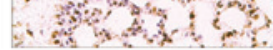

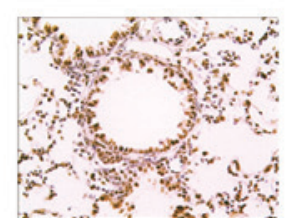

G
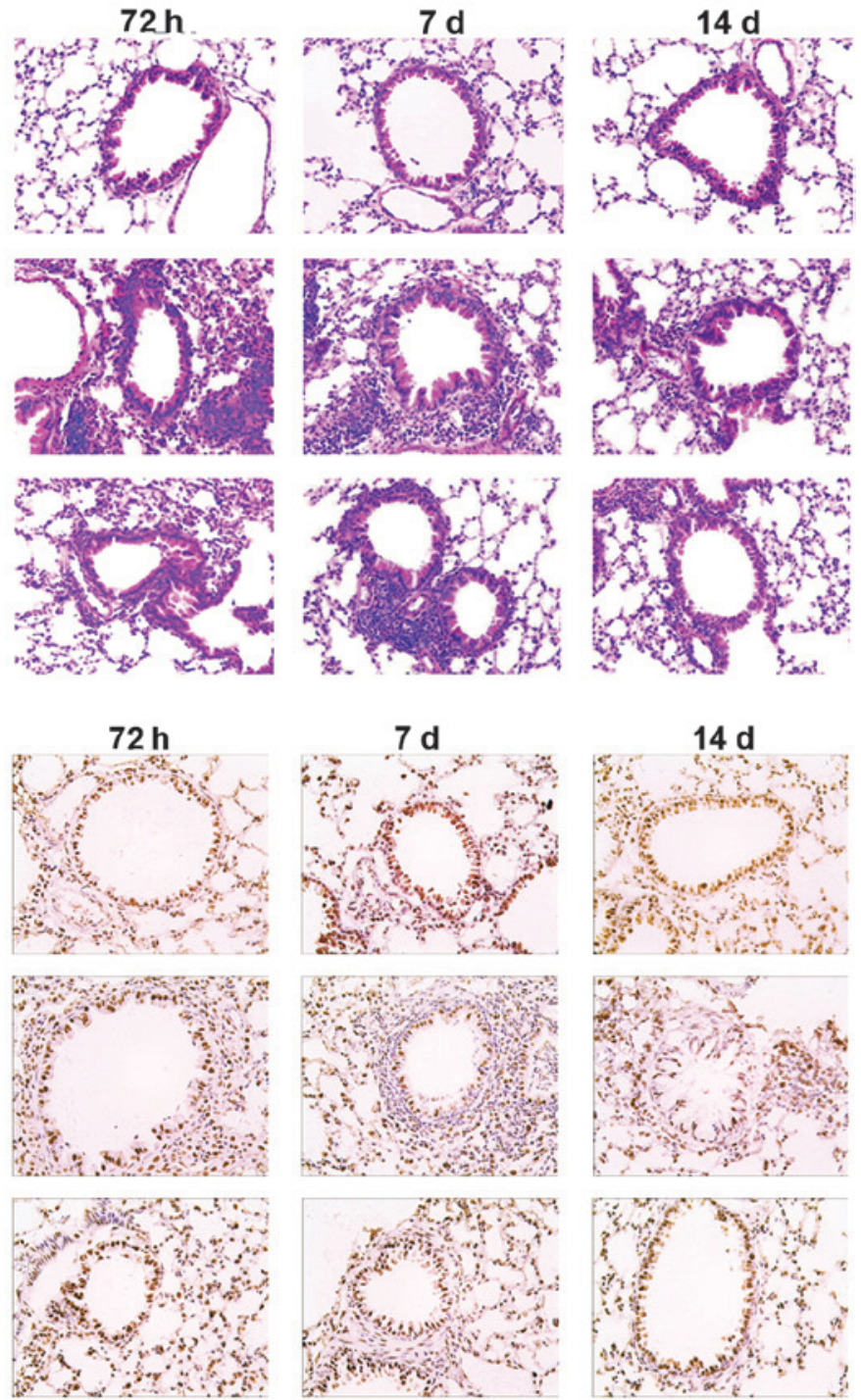

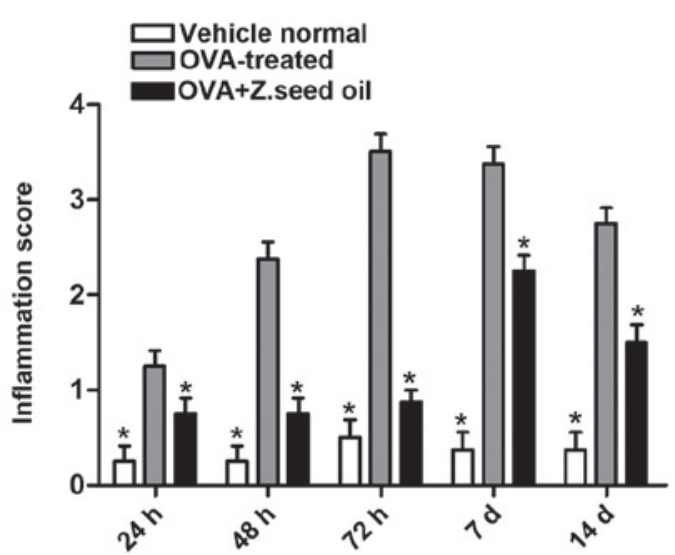

Figure 1. Effect of Z. seed oil on the lung histopathology of OVA-induced asthma and inflammation. Representative (A-C) hematoxylin and eosin (H\&E) and (D-F) proliferating cell nuclear antigen (DAB and H\&E) staining of lung sections following 24, 48 and $72 \mathrm{~h}$, and 7 and $14 \mathrm{~d}$ treatment (x200 magnification). (A and D) Vehicle control, (B and E) OVA-treated and (C and F) OVA + Z . seed oil-treated group. (G) Inflammation scores in the lung tissue of vehicle- , OVA- , and OVA $+\mathrm{Z}$. seed oil-treated mice. Data are presented as the mean \pm standard deviation $(\mathrm{n}=6)$. ${ }^{\text {"P }}<0.05$ vs. the OVA-treated group. d, days; OVA, ovalbumin; Z. seed oil, Zanthoxylum bungeanum seed oil.

observed at $48 \mathrm{~h}$, swollen bronchial epithelial cells, detachment of cells and hypertrophic sub-mucosal mucous glands with mucosal and sub-mucosal edema were observed. In Fig. 1B, a significant hyperplasia of bronchial smooth muscle cells, formation of lymph follicles and constricting of the bronchial airway due to increased cell mass were also demonstrated after $72 \mathrm{~h}$.

Following 7 days of sustained OVA challenge, the inflammatory infiltration score was $3.56 \pm 0.64$, suggesting that the inflammatory infiltration had not progressed past $72 \mathrm{~h}$ 
A

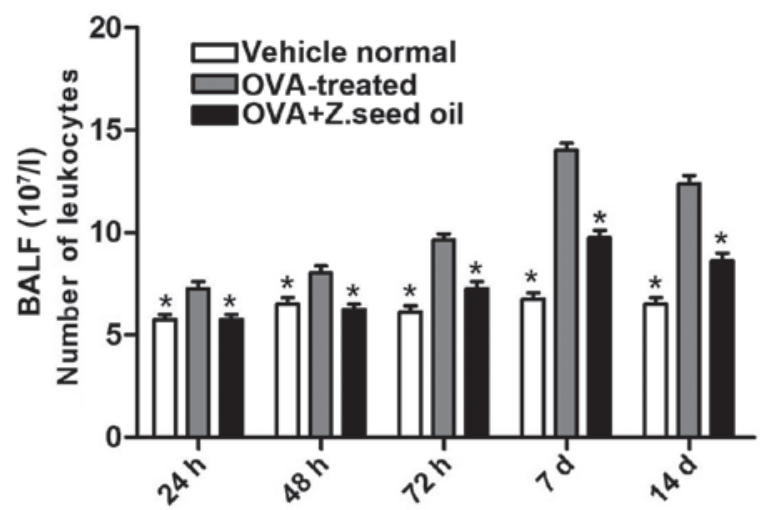

C

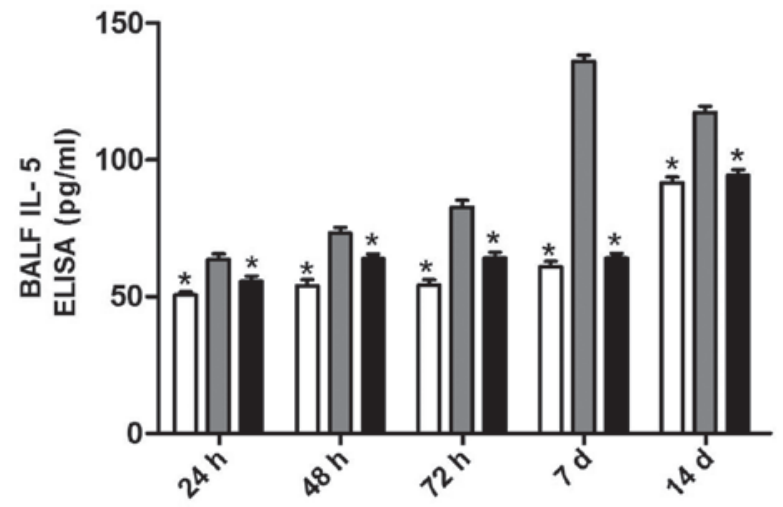

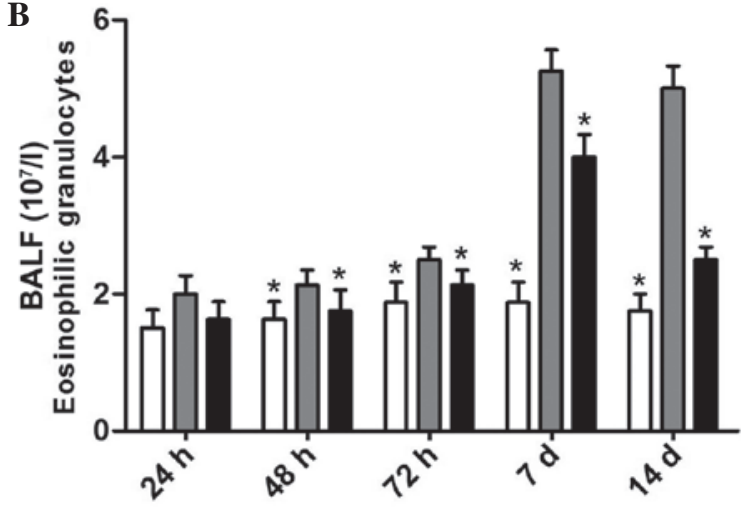

D

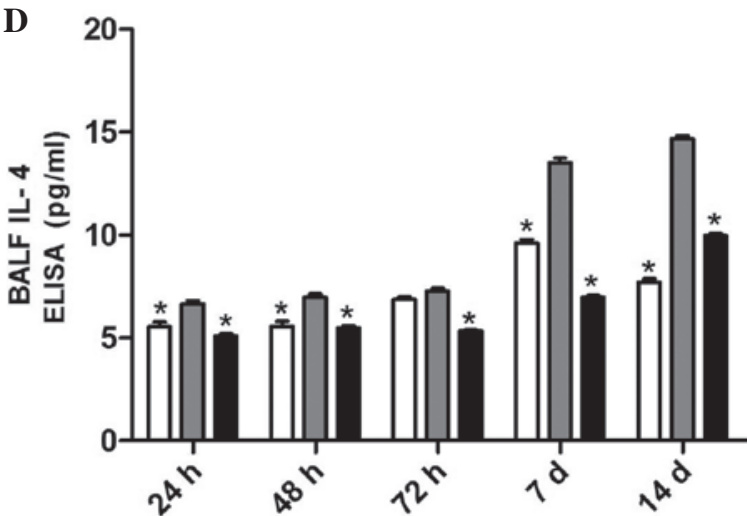

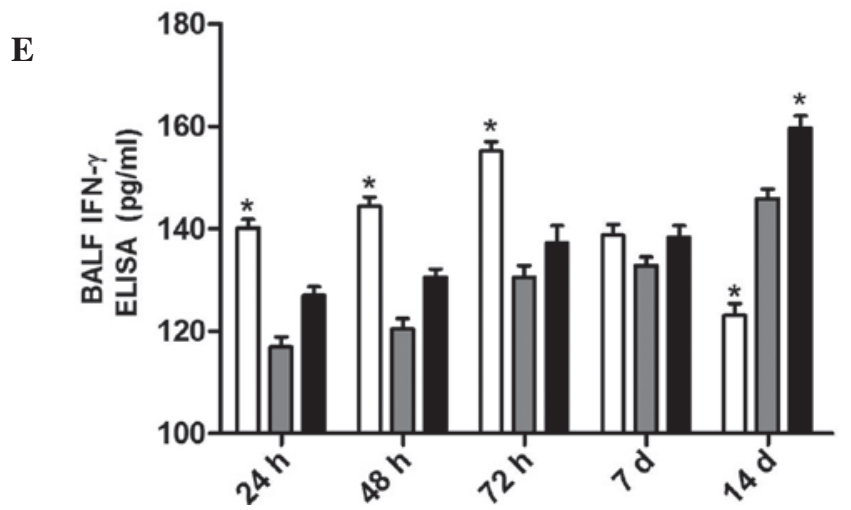

Figure 2. Effect of Z. seed oil on the recruitment of inflammatory cells, and IL-4, IL-5 and IFN $\gamma$ expression levels in the BALF of OVA-induced asthmatic mice. (A) Analysis of total leukocyte and (B) Eosinophil counts in the BALF of vehicle- , OVA- and OVA + Z. seed oil-treated mice. (C-E) Cytokine production in BALF collected after 24, 48, $72 \mathrm{~h}$, and 7 and $14 \mathrm{~d}$ treatment. Data represent the mean \pm standard deviation (n=8). ${ }^{*} \mathrm{P}<0.05$ vs. the OVA-treated group. OVA, ovalbumin; Z. seed oil, Zanthoxylum bungeanum seed oil; BALF, bronchoalveolar lavage fluid; d, days; IL, interleukin; IFN $\gamma$, interferon $\gamma$.

(Fig. 1G). The inflammatory response at day 7 appeared to induce airway remodeling, as bronchial smooth muscle hypertrophy and an increase in goblet cells were observed among changes in the ciliated epithelial cells and basement membrane thickening (Fig. 1B) compared with the vehicle-treated group (Fig. 1A). Following 14 days of sustained OVA challenge, inflammatory cell infiltration significantly decreased, with an infiltration score of $2.70 \pm 0.26$ compared with the vehicle-treated group $(0.50 \pm 0.26 ; \mathrm{P}<0.05$; Fig. 1G) and decreased compared with infiltration score at $72 \mathrm{~h}(3.56 \pm 0.64)$ and 7 days (3.36 \pm 0.64$)$. Bronchial smooth muscle hyperplasia markedly increased, with lymph follicles surrounding the airway. Furthermore, metaplasia of goblet cells in the tracheal and bronchial mucosa and increased bronchial epithelial cell proliferation in the OVA-challenged mice was observed (Fig. 1B) compared with the vehicle-treated group at 14 days (Fig. 1A).

Administration of $\mathrm{Z}$. seed oil ( $2 \mathrm{~g} / \mathrm{kg}$ ) to asthmatic mice significantly alleviated damage to the lung tissue. Leukocyte infiltration was markedly decreased in the Z. seed oil-treated mice (Fig. 1C), with significantly reduced infiltration scores at each time point compared with the OVA-treated group $(0.80 \pm 0.17$ at $24 \mathrm{~h}, 0.73 \pm 0.40$ at $48 \mathrm{~h}, 0.93 \pm 0.30$ at $72 \mathrm{~h}$, $2.20 \pm 0.52$ at 7 days and $1.5 \pm 0.30$ at 14 days; $P<0.05$; Fig. $1 G$ ). Pulmonary tissue injury was markedly alleviated, and airway remodeling, lymph follicles formation, goblet cells and bronchial epithelial cell hyperplasia were all reduced during the full time period compared with the vehicle-treated group (Fig. 1C). A reduction in PCNA staining in the bronchial and peribronchial epithelia of OVA-treated mice was detected 
A

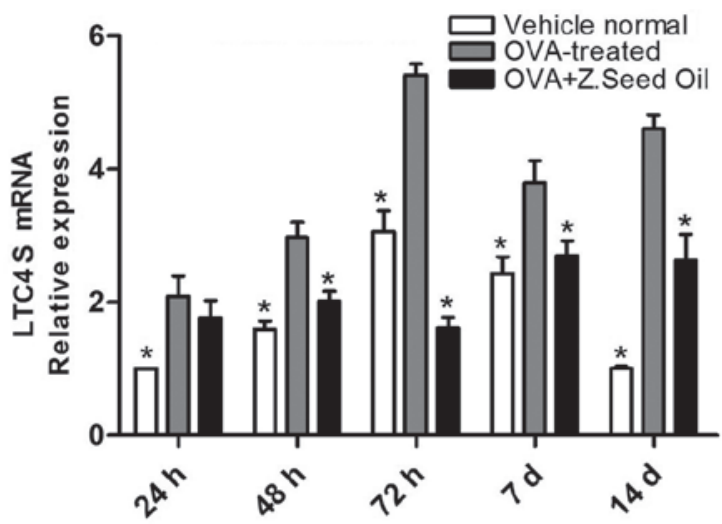

C

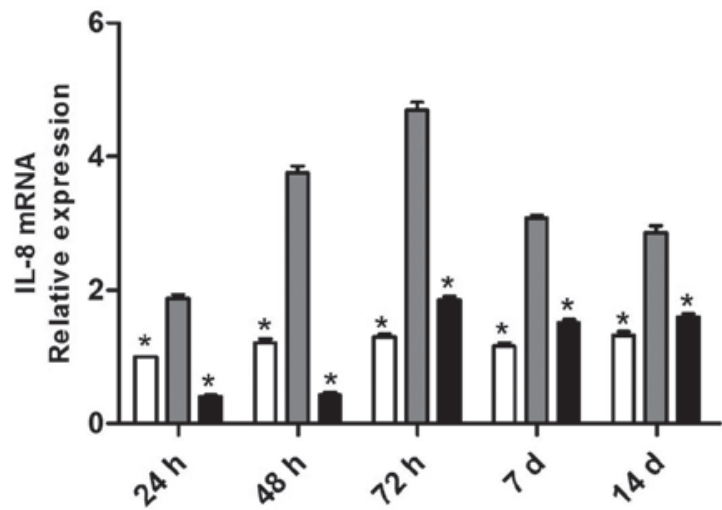

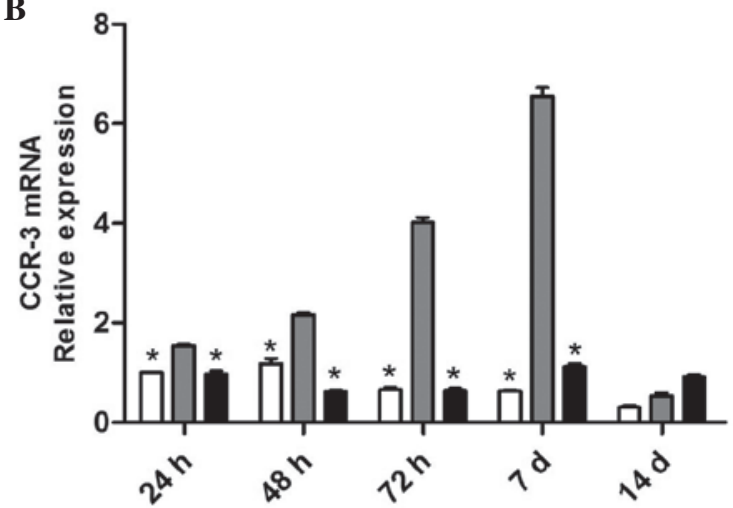

D

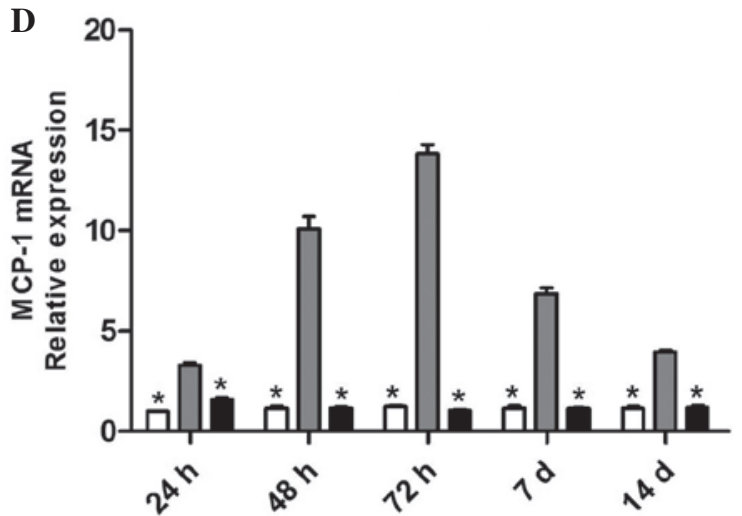

Figure 3. Effect of Z. seed oil on LTC4S, CCR-3, IL-8 and MCP-1 mRNA expression levels in the lung tissue of OVA-induced asthmatic mice. Lungs from vehicle- , OVA- and OVA + Z. seed oil-treated mice were excised following 24, 48 and $72 \mathrm{~h}$, and 7 and $14 \mathrm{~d}$ treatment. mRNA expression levels of (A) LTC4S, (B) CCR-3, (C) IL-8 and (D) MCP-1 were measured by RT-qPCR. Data are presented as the mean \pm standard deviation ( $\mathrm{n}=3$ ). ${ }^{*}<0.05$ vs. the OVA-treated group. OVA, ovalbumin; Z. seed oil, Zanthoxylum bungeanum seed oil; LTC4S, leukotriene C4 synthase; d, days; CCR-3, chemokine (C-C motif) receptor 3; IL-8, interleukin-8; MCP-1, monocyte chemoattractant protein-1.

(Fig. 1E) compared with the vehicle-treated mice (Fig. 1D). However, administration of $Z$. seed oil resulted in an increase in PCNA expression in the peribronchial epithelium and perivascular connective tissue at each time point (Fig. 1F) compared with the OVA-treated mice (Fig. 1E).

Z. seed oil inhibits the infiltration of total leukocytes and eosinophils into the airways. To examine the effect of $\mathrm{Z}$. seed oil on disease progression, leukocyte and eosinophil populations were analyzed in the BALF of $\mathrm{Z}$. seed oil- or placebo oil-treated mice. Administration of $\mathrm{Z}$. seed oil significantly reduced the total leukocyte population by $21-33 \%(\mathrm{P}<0.05$; Fig. 2A) and the eosinophil population by $5-51 \%(\mathrm{P}<0.05$; Fig. 2B) compared with the OVA-treated group. Additionally, the levels of IL-4, IL-5 and IFN $\gamma$ in the BALF were measured. Compared with the OVA-treated group, Z. seed oil reduced the levels of IL-5 levels by $13-53 \%(\mathrm{P}<0.05$; Fig. 2C) and IL-4 by $22-49 \%(\mathrm{P}<0.05$; Fig. $2 \mathrm{D})$ over the course of the experiment. The reduction of BALF IL-4 and IL-5 levels due to Z. seed oil administration was most pronounced after 7 days of sustained OVA challenge compared with the OVA-treated mice $(\mathrm{P}<0.05$; Fig. $2 \mathrm{C}$ and $\mathrm{D})$. Furthermore, administration of $\mathrm{Z}$. seed oil increased BALF IFN $\gamma$ levels by $6-8 \%$ over the course of the experiment (Fig. 2E). These results indicate that $Z$. seed oil attenuates the inflammatory response in asthmatic mice, particularly the infiltration of inflammatory cells and the production of inflammatory cytokines in the bronchial airway.
Z. seed oil treatment reduces $m R N A$ expression of chemotactic factor levels in the lungs of OVA-challenged mice. Environmental stress can lead to the production of chemotactic factors that promote the selective migration of eosinophils and neutrophils to the sites of inflammation $(23,24)$. mRNA expression levels were examined to identify whether Z. seed oil may affect the expression of the chemotactic factor leukotriene $\mathrm{C} 4$ synthase (LTC4S), IL-8, monocyte chemoattractant protein-1 (MCP-1) and chemokine (C-C motif) receptor-3 (CCR-3) in the lung tissue of asthmatic mice. LTC4S, IL-8, MCP-1 and CCR-3 mRNA expression levels were significantly upregulated in the lung tissue of the OVA-challenged mice compared with the vehicle-treated mice at all time points ( $\mathrm{P}<0.05$; Fig. 3$)$. Administration of Z . seed oil to the OVA-challenged mice significantly downregulated the levels of LTC4S, IL-8, MCP-1 and CCR-3 at 24, 48 and $72 \mathrm{~h}$, and 7 and 14 days $(\mathrm{P}<0.05$; Fig. 3), suggesting that $Z$. seed oil may attenuate the induction of chemotactic factors in the lung tissue of asthmatic mice.

Z. seed oil inhibits the induction of TNF- $\alpha$ and ICAM-1 protein and $m R N A$ expression in the lungs of asthmatic mice. Leukocyte recruitment and adhesion are required for sufficient immune surveillance and inflammatory response. The adhesion of leukocytes to the vascular endothelium is mediated by specific endothelial cell adhesion molecules, including ICAM-1, VCAM-1 and TNF- $\alpha$ (25-27). The expression levels of these adhesion molecules were analyzed in the 
A
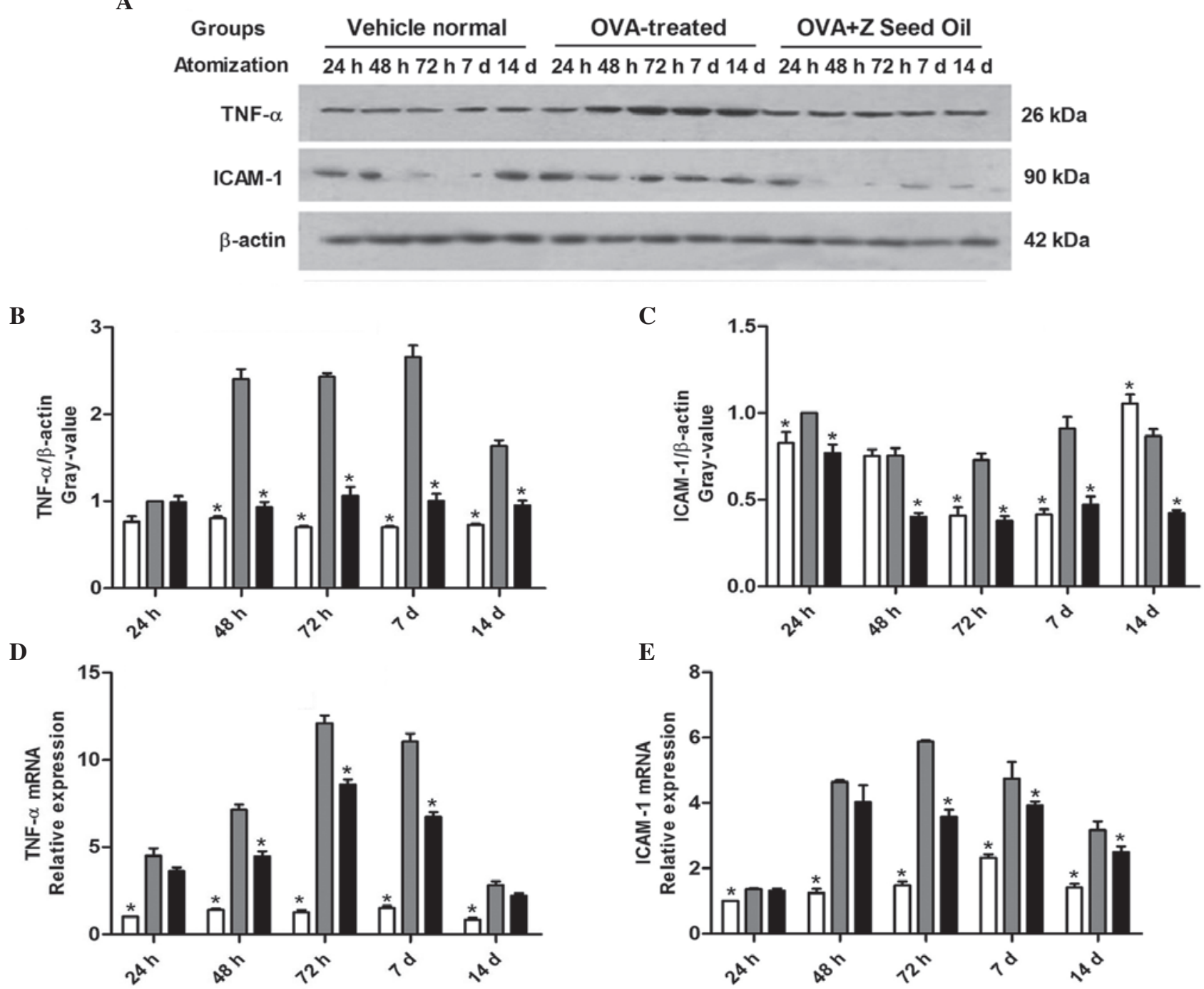

Figure 4. Effect of Z. seed oil on VCAM-1 TNF- $\alpha$ and ICAM-1 expression levels in the lung tissue of asthmatic mice. (A) Western blot analysis of TNF- $\alpha$, ICAM-1, and $\beta$-actin expression in vehicle- , OVA- and OVA + Z. seed oil-treated mice. Quantification of (B) TNF- $\alpha$ and (C) ICAM-1 protein expression levels. qPCR analysis of (D) TNF- $\alpha$ and (E) ICAM-1 mRNA expression levels. Data are expressed as the mean \pm standard deviation ( $\mathrm{n}=3$ ). "P<0.05 vs. the OVA-treated asthmatic mice. OVA, ovalbumin; Z. seed oil, Zanthoxylum bungeanum seed oil; d, days; TNF- $\alpha$, tumor necrosis factor- $\alpha$; ICAM-1, intercellular adhesion molecule-1.

lung tissue of asthmatic mice by western blotting (Fig. 4A-D) and RT-qPCR analyses (Fig. 4E and F). ICAM-1 and TNF- $\alpha$ protein and mRNA expression levels were significantly elevated in OVA-induced asthmatic mice compared with the vehicle-treated mice at the majority of time points $(\mathrm{P}<0.05$; Fig. 4), consistent with the increased inflammatory response observed. Administration of $\mathrm{Z}$. seed oil attenuated the induction of ICAM-1 and TNF- $\alpha$ mRNA and protein expression levels compared with the placebo-treated mice at 24, 48 and $72 \mathrm{~h}$, and 7 and 14 days $(\mathrm{P}<0.05$; Fig. 4C-F). These results suggest that $\mathrm{Z}$. seed oil inhibits the expression of adhesion molecules required for leukocyte recruitment, which may contribute to its anti-inflammatory effect.

Effect of Z. seed oil on the protein expression levels of TNF-R, $C D 14$, and TLR2 and 4 . The production of pro-inflammatory cytokines is controlled by the TNF-R, CD14, and TLR2 and 4 signal transduction pathways in human monocytes (28). Due to the marked inflammatory response in OVA-challenged mice, the expression levels of these signaling proteins were investigated in the presence and absence of Z. seed oil (Fig. 5A). Western blot analysis indicated a significant change in CD14 and TLR4 protein expression levels in only two of the five time points in the OVA-treated group compared with the vehicle-treated group (Fig. 5B and C). In addition, a significant change was observed in only three of the five time points following $\mathrm{Z}$. seed oil administration compared with the OVA-treated group (Fig. 5B and C). By contrast, the protein expression levels of TNF-R and TLR2 were significantly upregulated in the majority of time points in OVA-treated mice compared with the vehicle-treated mice ( $\mathrm{P}<0.05$; Fig. 5D and E). However, only the induction of TLR2 expression was significantly attenuated by $\mathrm{Z}$. seed oil administration ( $\mathrm{P}<0.05$; Fig. 5D), whereas TNF-R, CD14 and TLR4 expression levels were similar compared with the $\mathrm{Z}$. seed oil- or placebo oil-treated mice (Fig. 5B, C and E).

Effect of Z. seed oil on Ras protein expression levels and MAPK signaling in the lungs of asthmatic mice. The MAPK pathway 
A

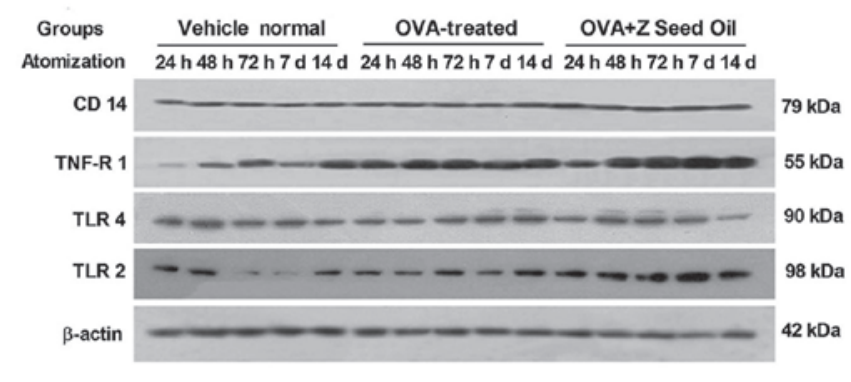

C

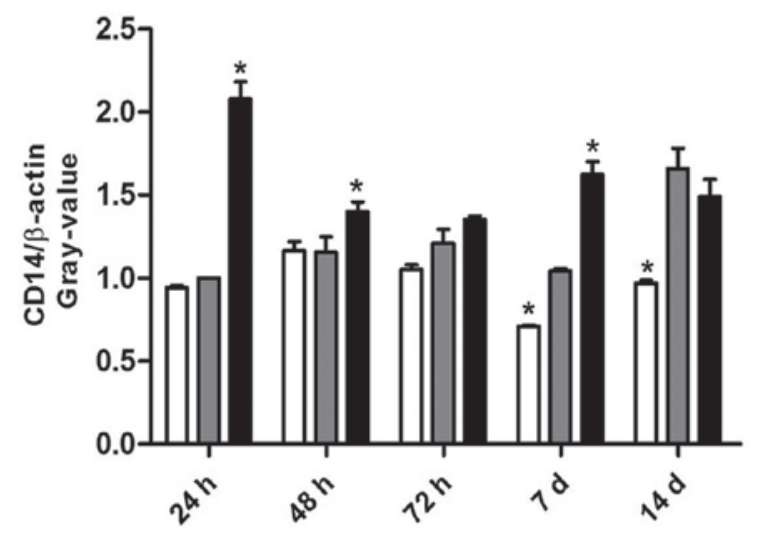

B
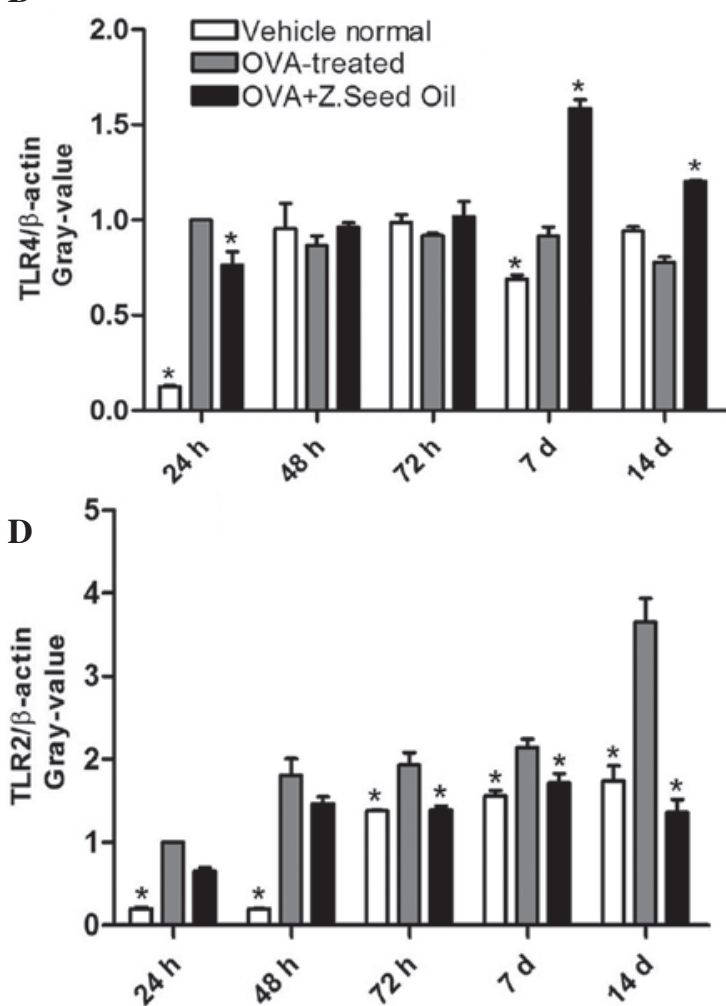

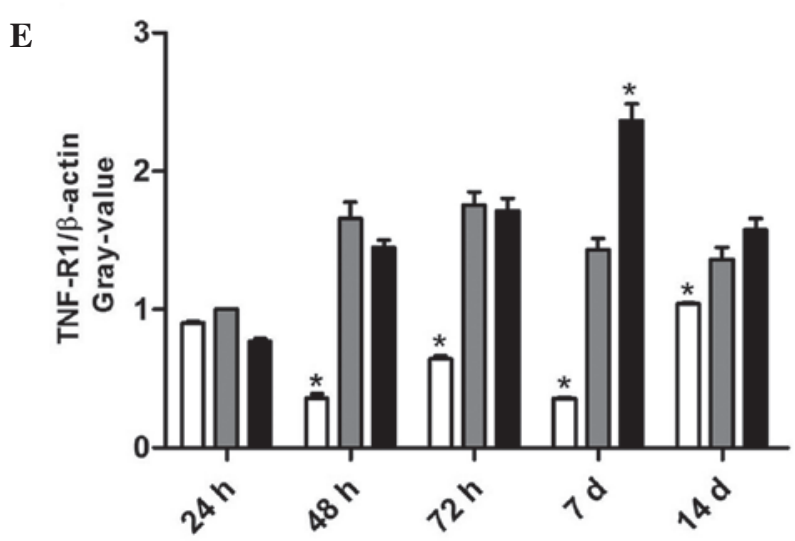

Figure 5. Effect of Z. seed oil on TLR4, CD14, TLR2 and TNF-R1 expression levels in OVA-induced asthmatic mice. (A) Western blot analysis of CD14, TNF-R1, TLR4, TLR2 and $\beta$-actin in vehicle- , OVA- and OVA + Z. seed oil-treated mice. Quantification of (B) TLR4, (C) CD14, (D) TLR2 and (E) TNF-R1. Expression levels were normalized to $\beta$-actin. Data are expressed as the mean \pm standard deviation $(\mathrm{n}=3)$. ${ }^{*} \mathrm{P}<0.05$ vs. the OVA-treated asthmatic mice. OVA, ovalbumin; Z. seed oil, Zanthoxylum bungeanum seed oil; d, days; TNF-R, tumor necrosis factor-receptor; TLR, toll-like receptor.

contributes to airway inflammation and AHR (29). The role of intracellular ERK1/2 signaling in the bronchial inflammatory response was observed in OVA-induced asthma and $\mathrm{Z}$. seed oil-treated mice. Western blot analysis (Fig. 6A) indicated that ERK1/2 phosphorylation was significantly increased in the lung tissue of asthmatic mice compared with control non-asthmatic mice at each time point $(\mathrm{P}<0.05$; Fig. $6 \mathrm{~B})$, indicating elevated ERK activity. Simultaneously, significantly elevated JNK phosphorylation and reduced p38 MAPK phosphorylation were detected in the lung tissue of asthmatic mice relative to the non-asthmatic control lungs at each time point analyzed $(\mathrm{P}<0.05$; Fig. $6 \mathrm{C}$ and D). Elevated ERK1/2 and JNK phosphorylation were sustained over the total of 14 days of OVA challenge, suggesting that these signaling pathways may contribute to the infiltration of inflammatory cells into the bronchial airway during asthma attacks. Administration of Z. seed oil significantly attenuated ERK and JNK phosphorylation in the lung tissue of asthmatic mice at each time point $(\mathrm{P}<0.05)$, but did not have an effect on Ras or p38 MAPK phosphorylation expression levels compared with the placebo oil-treated mice (Fig. 6C and E).

Z. seed oil attenuates the induction of nuclear ERK1/2 protein and $m R N A$ expression. In order to further evaluate the effect of Z. seed oil on ERK signaling in the lung tissue of the OVA-treated asthmatic mice, the levels of nuclear p-ERK and p-p38 MAPK were analyzed. Western blot analysis of lung nuclear protein extracts demonstrated significantly elevated ERK phosphorylation in the nuclei of lung cells from OVA-induced asthmatic mice compared with the 
A

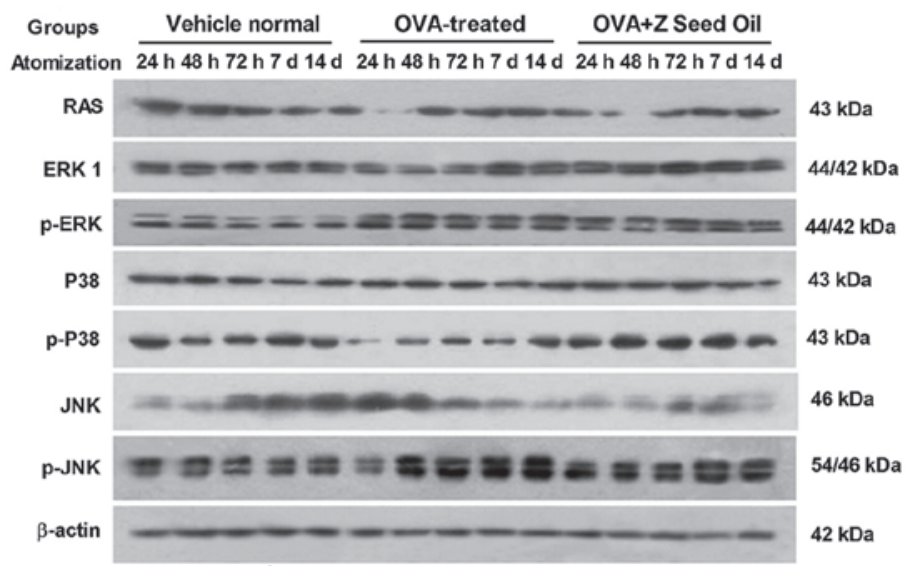

C

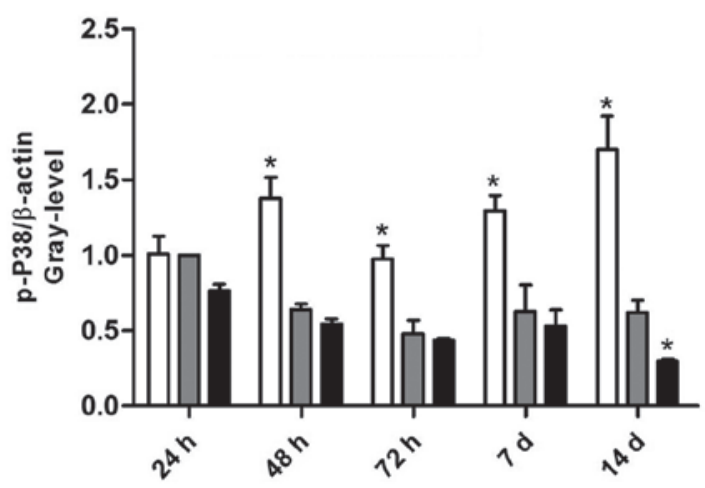

B

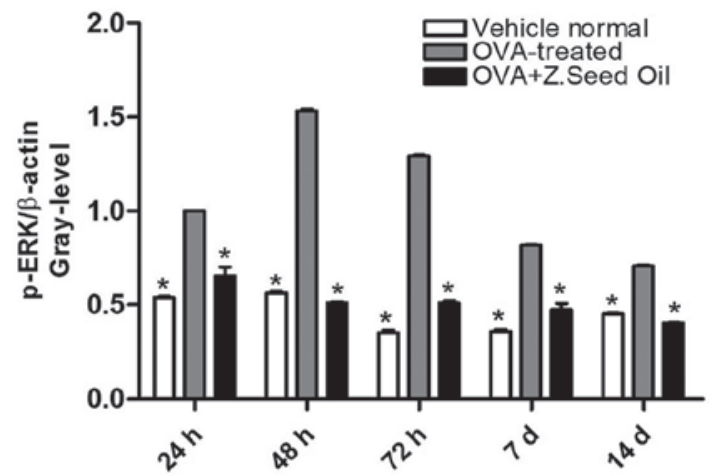

D

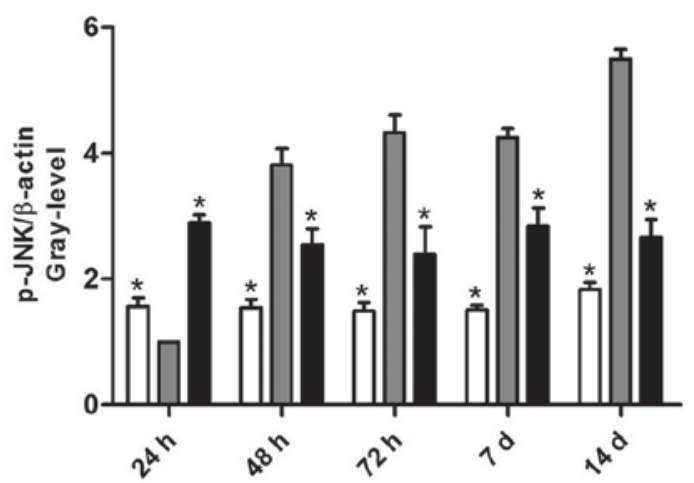

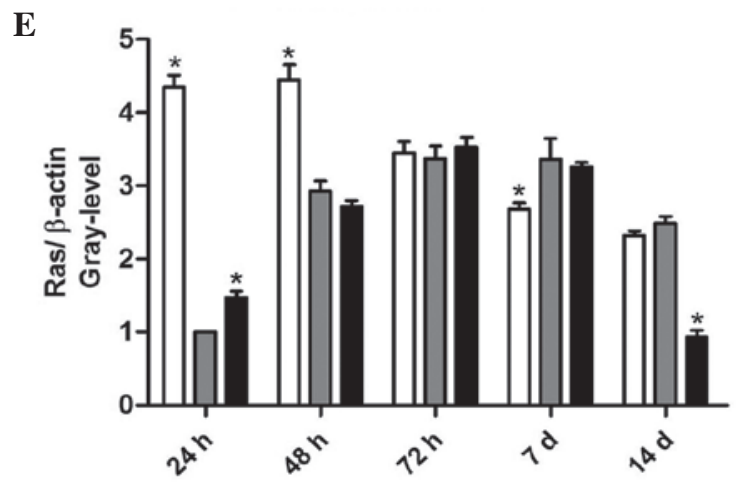

Figure 6. Effect of Z. seed oil on MAPK signaling in the lung tissue of OVA-induced asthmatic mice. (A) Western blot analysis of phosphorylated and unphosphorylated ERK1/2, p38 MAPK, JNK, Ras and $\beta$-actin expression in vehicle- , OVA- and OVA + Z. seed oil-treated mice. Quantitative analysis of the expression levels of (B) p-ERK1/2, (C) p-p38 MAPK, (D) p-JNK and (E) Ras. Protein expression levels were normalized to $\beta$-actin. Data are expressed as the mean \pm standard deviation $(\mathrm{n}=3)$. ${ }^{*} \mathrm{P}<0.05$ vs. the OVA-treated asthmatic mice. OVA, ovalbumin; $\mathrm{Z}$. seed oil, Zanthoxylum bungeanum seed oil; $\mathrm{d}$, days; p-ERK, phosphorylated-extracellular signal regulated kinase; JNK, c-jun N-terminal kinase.

non-asthmatic control mice ( $\mathrm{P}<0.05 ;$ Fig. 7A and B). Compared with the non-asthmatic mice, phosphorylation of p38 MAPK was significantly reduced at $72 \mathrm{~h}, 7$ and 14 days of sustained OVA challenge $(\mathrm{P}<0.05$; Fig. $7 \mathrm{C}$ and $\mathrm{D})$. These changes in ERK1/2 phosphorylation were attenuated and p38 MAPK phosphorylation was upregulated by Z. seed oil treatment. The results suggest that nuclear translocation of ERK1/2 is enhanced in the lung tissue of asthmatic mice, consistent with elevated MAPK activity following asthma induction.

To further support the western blot analysis data, ERK and p38 MAPK mRNA expression levels were measured in the lung tissue of asthmatic mice over the course of the experiment. Consistent with the protein analysis, ERK mRNA expression levels were significantly upregulated $(\mathrm{P}<0.05$; Fig. 7E), and p38 MAPK mRNA levels were significantly downregulated $(\mathrm{P}<0.05$; Fig. 7F) in the lung tissue of OVA-induced asthmatic mice compared with the non-asthmatic mice. Administration of Z. seed oil reduced ERK and elevated p38 MAPK mRNA expression levels in the lung tissue of asthmatic mice compared with the untreated OVA-challenged mice at each time point $(\mathrm{P}<0.05$; Fig. 7E and F).

$Z$. seed oil regulates nuclear $N F-\kappa B$ expression. To assess the effect of Z. seed oil on other inflammatory pathways, c-fos, $\mathrm{c}-\mathrm{JUN}, \mathrm{ATF}-2$ and NF- $\mathrm{BB}$ nuclear levels were measured in the lung tissue of asthmatic mice by western blotting (Fig. 8A). OVA-induced asthma resulted in the significant upregulation of c-fos nuclear levels at 24, 48 and $72 \mathrm{~h}$ time points (Fig. 8B), 
A

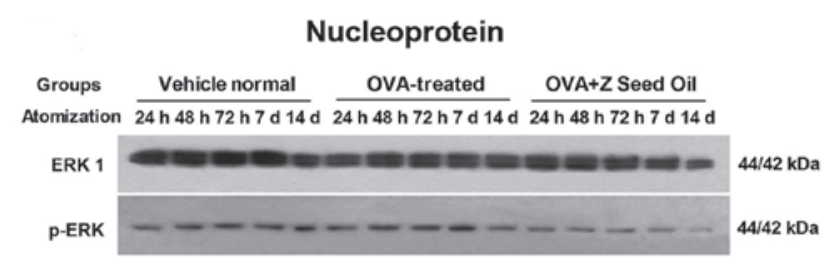

C

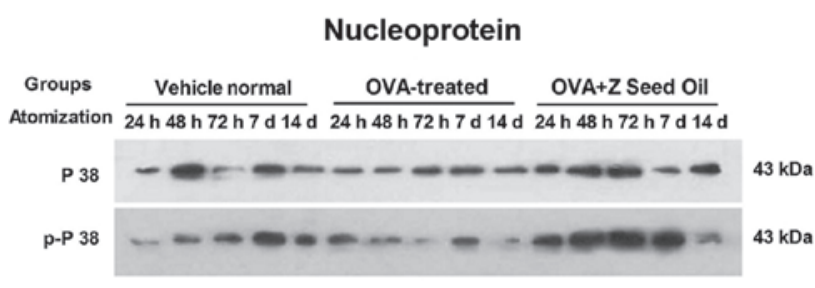

$\mathbf{E}$

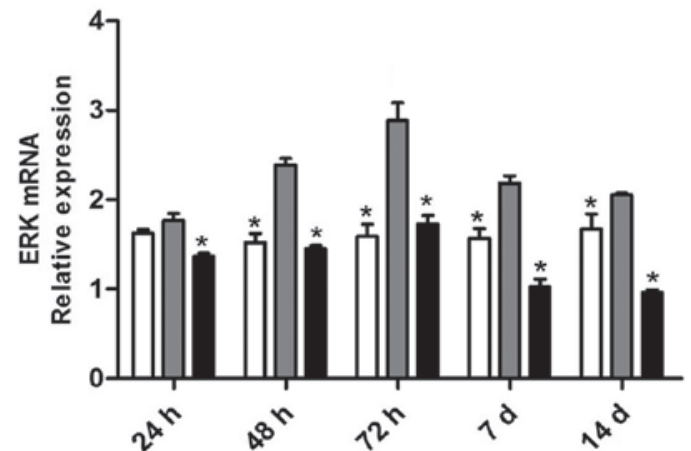

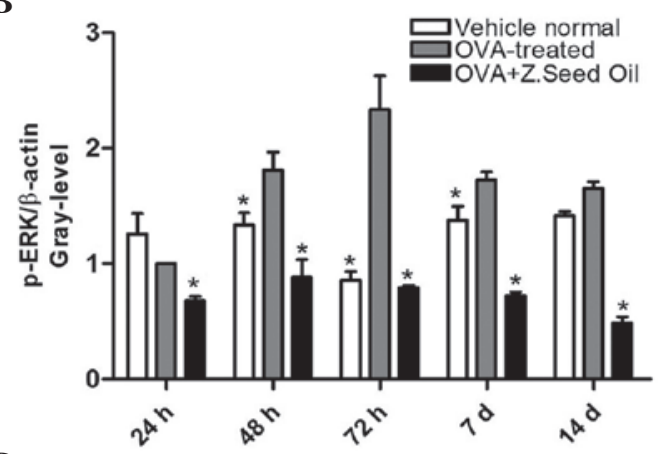

D
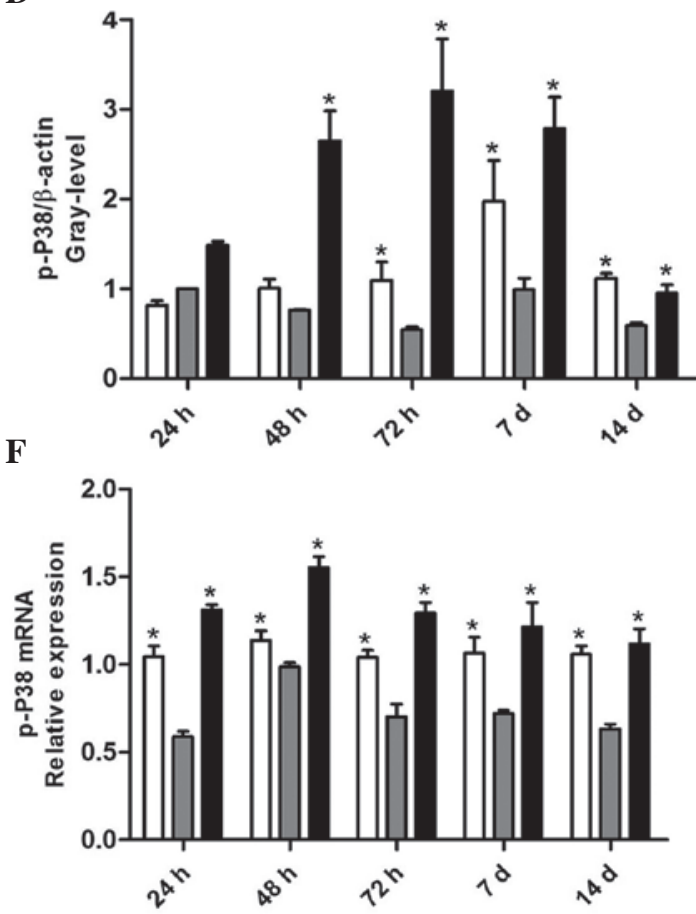

Figure 7. Effect of Z. seed oil on ERK1/2 and p38 MAPK nuclear levels in the lung tissue of OVA-induced asthmatic mice. Western blot analysis and quantification of (A and B) ERK1/2 and (C and D) p38 MAPK expression and phosphorylation levels in nuclear extracts from vehicle- , OVA- and OVA + Z. seed oil-treated mice. Protein expression levels were normalized to $\beta$-actin. qPCR analysis of (E) ERK1/2 and (F) p38 MAPK mRNA expression levels. Data are expressed as the mean \pm standard deviation $(\mathrm{n}=3)$. ${ }^{*} \mathrm{P}<0.05$ vs. the OVA-treated asthmatic mice. OVA, ovalbumin; Z. seed oil, Zanthoxylum bungeanum seed oil; d, days; p-ERK, phosphorylated-extracellular signal regulated kinase.

and c-JUN nuclear levels at 24, $72 \mathrm{~h}$ and 7 days (Fig. 8C) compared with the non-asthmatic mice $(\mathrm{P}<0.05)$. Furthermore, a decrease in the levels of p-NF- $\kappa$ B-p65 (Fig. 8D) and p-ATF-2 (Fig. 8E) were observed in the nuclear extracts from the lung tissue of asthmatic mice compared with the non-asthmatic mice $(\mathrm{P}<0.05)$. Administration of $\mathrm{Z}$. seed oil to asthmatic mice significantly attenuated c-fos (Fig. 8B) and c-JUN (Fig. 8C) induction $(\mathrm{P}<0.05)$, suggesting that this treatment may inhibit the transcription of pro-inflammatory factors in nuclear extracts from the lung tissue of asthmatic mice compared with the placebo oil-treated mice.

\section{Discussion}

Asthma is a chronic disease of the lungs characterized by bronchial inflammation and AHR. Lung biopsies from asthmatic patients demonstrate significant infiltration of eosinophils, lymphocytes, macrophages and mast cells into the bronchial airway. This inflammatory response is accompanied by structural changes, including thickening of the epithelial lining of the airway, sub-epithelial fibrosis, and hyperplasia of goblet cells and airway smooth muscle cells (airway remodeling). Considering the prominent inflammatory response in asthma, the majority of asthma therapies employ anti-inflammatory agents (30-32).

In the current study, the therapeutic potential and anti-inflammatory effect of $\mathrm{Z}$. seed oil was examined in mice with asthma induced by sustained OVA challenge. Intraperitoneal injection of OVA followed by sustained challenge with intranasal administration of OVA is known to induce the expansion of the Th2 lymphocyte population and production of Th2 cytokines, leading to AHR and inflammation. This inflammation is typically characterized by eosinophil infiltration, production of OVA-specific antibodies (IgE) (33), and production of IL-4, IL-5, IL-9 and IL-13 (34). The present study identified that sustained OVA exposure induces a massive influx of lymphocytes, eosinophils, neutrophils and mononuclear cells in the lung tissue of mice. Furthermore, 
A

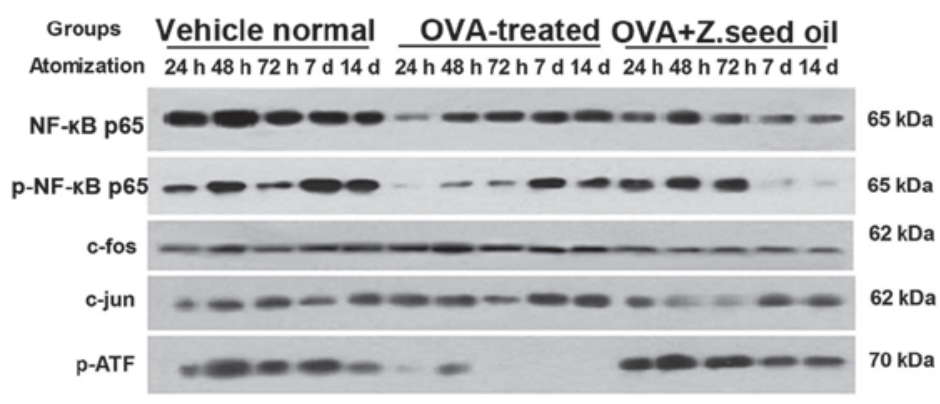

C

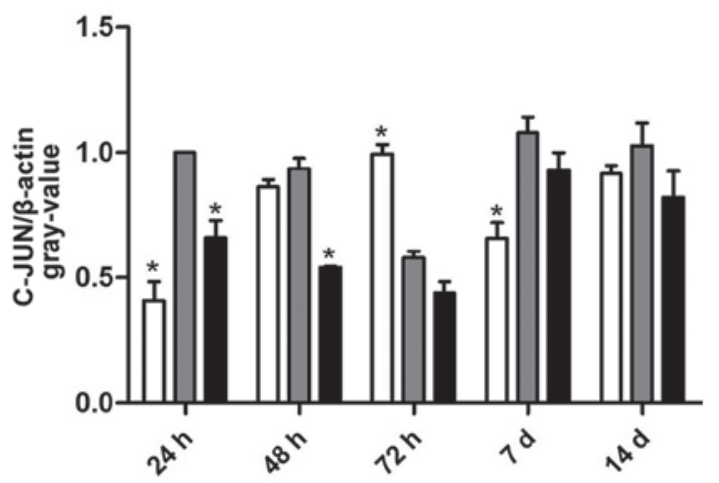

B

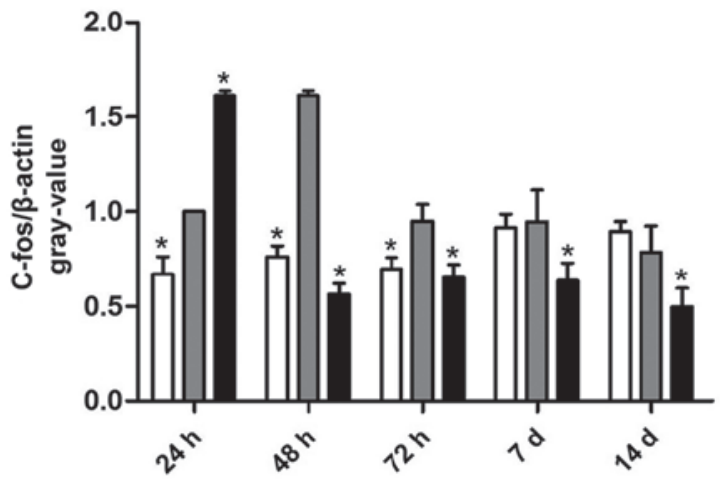

D

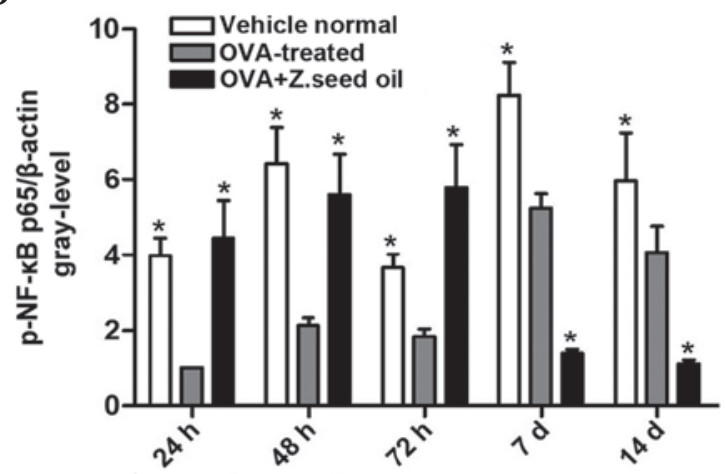

$\mathbf{E}$

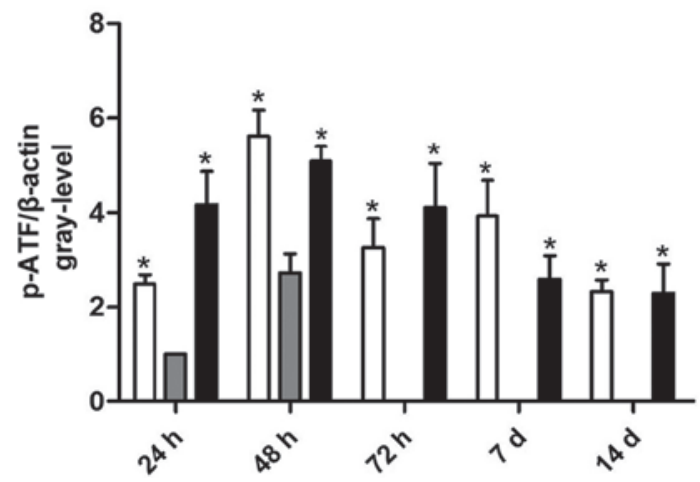

Figure 8. Effect of Z. seed oil on nuclear NF- $\kappa$ B signaling in the lung tissue of asthmatic mice. (A) Western blot analysis of NF- $\mathrm{B}$ p65, p-NF- $\kappa \mathrm{B}$ p65, c-fos, c-JUN, p-ATF-2 and $\beta$-actin protein expression levels in vehicle- , OVA- and OVA + Z. seed oil-treated. Quantitative analysis of (B) p-c-fos, (C) p-c-JUN, (D) $\mathrm{p}-\mathrm{NF}-\kappa \mathrm{B}$ p 65 and (E) p-ATF-2 expression levels. Protein expression levels were normalized to $\beta$-actin. Data are expressed as the mean \pm standard deviation $(\mathrm{n}=3)$. ${ }^{*} \mathrm{P}<0.05$ vs. the OVA-treated asthmatic mice. OVA, ovalbumin; Z. seed oil, Zanthoxylum bungeanum seed oil; d, days; $\mathrm{p}-\mathrm{NF}-\kappa \mathrm{B}$, nuclear factor- $\kappa \mathrm{B}$; ATF, activating transcription factor.

OVA exposure led to the induction of the pro-inflammatory cytokines TNF- $\alpha$, IL-4 and IL-5, and reduced levels of IFN $\gamma$ in the BALF of asthmatic mice. These cytokines serve an important role in the initiation and pathophysiology of asthma, including airway remodeling, IgE production and eosinophil function (35). Administration of $\mathrm{Z}$. seed oil to the asthmatic mice effectively inhibited the influx of inflammatory cells into the lungs, as the total leucocyte and eosinophil populations in the lung tissue were significantly reduced. The reduction in infiltration and damage was accompanied by a decrease in IL-4 and IL-5 levels, and an increase in the IFN $\gamma$ levels in the BALF of Z. seed-treated mice. These results suggest that $Z$. seed oil suppresses the Th2 cell population in asthmatic lung tissue, while the elevated IFN $\gamma$ levels are consistent with a reduction in the eosinophil population. The $Z$. seed oil-induced reduction of T-helper lymphocytes and increase of IFN $\gamma$ production may reflect an imbalance in the Th1 and Th2 cytokine profile of the lungs. Thus, $Z$. seed oil may reduce atopic inflammation in asthma by inhibiting Th2 cell activity, resulting in decreased IL-4 and IL-5 production.

Chemotaxis is an important step in the migration of inflammatory cells to sites of inflammation. Although the precise role of IL- 8 in lung disease is unclear, this cytokine serves a pivotal role in innate immunity by recruiting immune cells, such as neutrophils and monocytes, to the sites of inflammation (36). Furthermore, IL-8 is associated with neutrophil inflammation in the respiratory tract, particularly in cases of severe, persistent asthma (37). Eosinophils are attracted to the site of inflammation in the bronchial airway by chemokines, such as eotaxin and chemokine (C-C motif) ligand 5 [also 
known as regulated on activation, normal T cell expressed and secreted], which bind to the chemokine receptor CCR-3 (38). These chemokines and their receptors may serve a significant role in the pathogenesis of asthma.

The current study demonstrated that OVA-induced asthma promotes the expression of IL-8, MCP-1, CCR-3 and LTC4S, suggesting that these genes are involved in the development of asthma following OVA exposure. These results were consistent with the increased inflammatory response observed in the mouse model. The induction of IL-8 MCP-1, CCR-3, LTC4S and TNF- $\alpha$ were effectively inhibited by the Z. seed oil treatment. TNF- $\alpha$ promotes inflammation, leukocyte infiltration and stimulates cytokine production $(39,40)$. Thus, $Z$. seed oil may prevent the induction of genes regulating the cytokine response, which likely contributes to its anti-inflammatory effect.

The current study indicated that ICAM-1 expression was upregulated in the lung tissue of asthmatic mice, and may contribute to the inflammatory response by promoting adhesion of inflammatory cells. ICAM-1 is an adhesion protein that is expressed in various types of cells, including endothelial and epithelial cells, leukocytes, and fibroblasts. In particular, inflammatory cytokines can promote ICAM-1 expression, thus augmenting the immune response and leukocyte accumulation $(41,42)$. Administration of $\mathrm{Z}$. seed oil attenuated the induction of TNF- $\alpha$ and ICAM-1 following OVA-induced asthma. These results suggest that $Z$. seed oil may suppress the induction of adhesion molecules that contribute to eosinophil and neutrophil infiltration into the bronchial airway pathway, consequently inhibiting the development of asthma.

TLRs are an evolutionarily conserved family of cell surface molecules that participate in the innate immune recognition of pathogens $(43,44)$. There are two major pathways involved in TLR signal transduction. The MyD88-dependent pathway recruits IL-1 receptor-associated kinase (IRAK) 4, IRAK1 and TNF-R-associated factor 6 to activate transcription factors, and trigger the release of pro- and anti-inflammatory cytokines (1). The present study demonstrated that TLR2 and TNF-R1 expression levels were significantly increased in the lung tissue of asthmatic mice, compared with the TLR4 and CD14 expression levels. The results indicate that TLR2 and TNF-R1 were selectively activated in response to the sustained OVA challenge, implicating these pathways in the pro-inflammatory signaling of asthma.

The MAPK signaling pathway serves a role in the immune response by regulating gene expression, as well as cell proliferation, survival, death and mobility (45). The phosphorylation of numerous components of the MAPK system (ERK, p38 MAPK and JNK) are upregulated in animal models of asthma. In turn, MAPK enhances transcriptional activation protein-1, ATF-2 and c-JUN, leading to cytokine production, and differentiation and proliferation of inflammatory cells (12). The ERK1/2 selective inhibitor U0126 significantly blocks antigen-induced airway inflammatory cell infiltration, and the production of IL-4, IL-5, eotaxin, serum antigen-specific IgE and mucus in BALF, while decreasing VCAM-1 expression and AHR in a dose-dependent manner (28).

In the current study, p-ERK1/2 and p-JNK levels were significantly increased in the lung tissue of OVA-induced asthmatic mice. Furthermore, nuclear ERK1/2 phosphorylation was demonstrated to be induced and p38 MAPK was downregulated by OVA treatment. These results suggest that the transcriptional activity of ERK and JNK, but not p38 MAPK, are induced in OVA-stimulated asthmatic lung tissue. Downstream of ERK1/2 and JNK, c-fos and c-JUN levels were increased, while downstream of p38 MAPK, p-ATF-2 levels were decreased. However, no significant change in $\mathrm{NF}-\kappa \mathrm{B}$ expression was observed in the asthmatic lung tissue. The upregulation of the ERK1/2 and JNK expression levels possibly occurred at the transcriptional level, as an increase in the mRNA expression levels was detected for the genes of interest in the asthmatic lung tissue. These data suggest that the ERK1/2 and JNK signaling cascades, but not p38 MAPK, may provide a therapeutic target for the treatment of asthma. Additionally, administration of $\mathrm{Z}$. seed oil significantly reduced ERK1/2 and JNK phosphorylation following OVA exposure. Consistent with the reduced phosphorylation, the nuclear levels of c-fos and c-JUN were downregulated in the lung tissue of Z. seed oil-treated mice. The inhibition of ERK and JNK signaling may be responsible for the reduction of inflammatory cytokine production (IL-8, MCP-1 and TNF- $\alpha$ ) and ICAM-1 expression in the lung tissue following $\mathrm{Z}$. seed oil treatment. The present study demonstrated that $Z$. seed oil elevated p-p38 MAPK and p-ATF-2 levels, suggesting that there is a selective contribution of each of the MAPKs in the inflammatory response of OVA-induced asthma.

In conclusion, Z. seed oil has a profound therapeutic effect on airway inflammation and AHR in the murine model of asthma used in the current study. Z. seed oil significantly attenuates the inflammatory response to sustained OVA exposure, including inflammatory cell infiltration into the bronchial airway, and induction of inflammatory cytokines and adhesion molecules. Z. seed oil appears to exert its anti-inflammatory effect partially through the suppression of ERK and JNK signaling. Thus, the therapeutic activity of Oriental medicines that employ Z. seed oil may be partially due to: i) Immuno-modulatory agents contained in $Z$. seed oil that reduce $T h 2$ cell immune responses; or ii) reduced production of pro-inflammatory cytokines, chemokines and adhesion molecules that attenuate the recruitment of inflammatory cells to OVA exposed lung tissue. Thus, the present study demonstrated that Z. seed oil may serve as a therapeutic agent for the prevention or treatment of allergen-induced asthma disease and that future studies may provide novel therapeutic strategies for asthma.

\section{References}

1. Takeda M, Ito W, Tanabe M, Ueki S, Kato H, Kihara J, Tanigai T, Chiba T, Yamaguchi K, Kayaba H, et al: Allergic airway hyperresponsiveness, inflammation, and remodeling do not develop in phosphoinositide 3-kinase $\gamma$-deficient mice. J Allergy Clin Immunol 123: 805-812, 2009.

2. Akbari O, Faul JL, Hoyte EG, Berry GJ, Wahlström J, Kronenberg M, DeKruyff RH and Umetsu DT: CD4+ invariant T-cell-receptor ${ }^{+}$natural killer $\mathrm{T}$ cells in bronchial asthma. N Engl J Med 354: 1117-1129, 2006.

3. Elias JA, Lee CG, Zheng T, Ma B, Homer RJ and Zhu Z: New insights into the pathogenesis of asthma. J Clin Invest 111: 291-297, 2003.

4. Expert Panel Report 3 (EPR-3): Guidelines for the diagnosis and management of asthma-summary report 2007. J Allergy Clin Immunol 120: S94-S138, 2007.

5. Torén $\mathrm{K}$ and Hermansson BA: Incidence rate of adult-onset asthma in relation to age, sex, atopy and smoking: A Swedish population-based study of 15813 adults. Int J Tuberc Lung Dis 3: 192-197, 1999. 
6. de Marco R, Locatelli F, Cazzoletti F, Bugianio M, Carosso A and Marinoni A: Incidence of asthma and mortality in a cohort of young adults: A 7-year prospective study. Respir Res 6: 95, 2005.

7. Karjalainen A, Kurppa K, Martikainen R, Klaukka T and Karjalainen J: Work is related to a substantial portion of adult-onset asthma incidence in the Finnish population. Am J Respir Crit Care Med 164: 565-568, 2001.

8. National Heart Blood and Lung Institute: Guidelines for the diagnosis and management of asthma. National Institutes of Health, Bethesda, USA, 2002

9. Duan W, Chan JH, Wong CH, Leung BP and Wong WS: Anti-inflammatory effects of mitogen-activated protein kinase kinase inhibitor U0126 in an asthma mouse model. J Immunol 172: 7053-7059, 2004.

10. Pelaia G, Cuda G, Vatrella A, Gallelli L, Caraglia M, Marra M, Abbruzzese A, Caputi M, Maselli R, Costanzo FS, et al: Mitogen-activated protein kinases and asthma. J Cell Physiol 202: 642-653, 2005

11. Kumar A, Lnu S, Malya R, Barron D, Moore J, Corry DB and Boriek AM: Mechanical stretch activates nuclear factor-kappaB, activator protein-1, and mitogen-activated protein kinases in lung parenchyma: Implications in asthma. FASEB J 17: 1800-1811, 2003.

12. Dong C, Davis RJ and Flavell RA: MAP kinases in the immune response. Annu Rev Immunol 20: 55-72, 2002.

13. Atherton HC, Jones G and Danahay H: IL-13-induced changes in the goblet cell density of human bronchial epithelial cell cultures: MAP kinase and phosphatidylinositol 3-kinase regulation. Am J Physiol Lung Cell Mol Physiol 285: L730-L739, 2003.

14. Yamashita M, Kimura M, Kubo M, Shimizu C, Tada T, Perlmutter RM and Nakayama T: T cell antigen receptor-mediated activation of the Ras/mitogen-activated protein kinase pathway controls interleukin 4 receptor function and type- 2 helper $\mathrm{T}$ cell differentiation. Proc Natl Acad Sci USA 96: 1024-1029, 1999.

15. Rahman MT, Alimuzzaman M, Ahmad S and Chowdhury AA: Antinociceptive and antidiarrhoeal activity of Zanthoxylum rhetsa. Fitoterapia 73: 340-342, 2002.

16. Chang CT, Doong SL, Tsai IL and Chen IS: Coumarins and anti-HBV constituents from Zanthoxylum schionifolium. Phytochemistry 45: 1419-1422, 1997.

17. Bracke ME, Depypere HT, Boterberg T, Van Marck VL, Veenekens KM, Vanleuchene E, Nuytinck M, Serreyn R and Mareel MM:. Influence of tangeretin on tamoxifen's therapeutic benefit in mammary cancer. J Nat Cancer Inst 91: 354-359, 1999.

18. Tanaka S, Sato T, Akimoto N, Yano M and Ito A: Prevention of UVB-induced photoinflammation and photoaging by a polymethoxy flavonoid, nobiletin, in human keratinocytes in vivo and in vitro. Biochem Pharmacol 68: 433-439, 2004

19. Tan GT, Pezzuto JM, Kinghorn AD and Hughes SH: Evaluation of natural products as inhibitors of human immunodeficiency virus type 1 (HIV-1) reverse transcriptase. J Nat Prod 54: 143-154, 1991

20. Xia L, You J,LiG, SunZ and Suo Y: Compositional and antioxidant activity analysis of Zanthoxylum bungeanum seed oil obtained by supercritical CO2 fluid extraction. J Am Oil Chem Soc 88: 23-32, 2011.

21. Myou S, Leff AR, Myo S, et al: Blockade of inflammation and airway hyperresponsiveness in immune-sensitized mice by dominant-negative phosphoinositide 3-kinase-TAT. J Exp Med 17; 198(10): 1573-82, 2003.

22. Livak KJ and Schmittgen TD: Analysis of the relative gene expression data using real-time quantitative PCR and the 2(-Delta Delta C(T)) method. Methods 25: 402-408, 2001.

23. Murphy PM: Chemokine receptors: Structure, function and role in microbial pathogenesis. Cytokine Growth Factor Rev 7: 47-64, 1996.

24. Foessmann UUM, Loetscher P, Dahinden CA, Langen $H$, Thelen M and Baggiolini M: Eotaxin-2s like eotaxin on human eosinophil and receptor. J Exp Med 183: 2349-2354, 1997.
25. Alam R, York J, Boyars M, Stafford S, Grant JA, Lee J, Forsythe P, Sim T, Ida N: Increased MCP-1, RANTES, and MIP-1alpha in bronchoalveolar lavage fluid of allergic asthmatic patients. Am J Respir Crit Care Med 153: 1398-1404

26. Parent $C$ and Eichacker PQ: Neutrophil and endothelial cell interactions in sepsis. The role of adhesion molecules. Infect Dis Clin North Am 13: 427-447, 1999.

27. Shanley TP, Warner RL and Ward PA: The role of cytokines and adhesion molecules in the development of inflammatory injury. Mol Med Today 1: 40-45, 1995.

28. Asea A, Kraeft SK, Kurt-Jones EA, Stevenson MA, Chen LB, Finberg RW, Koo GC and Calderwood SK: HSP70 stimulates cytokine production through a CD14-dependant pathway, demonstrating its dual role as a chaperone and cytokine. Nat Med 6: 435-442, 2000.

29. Duan W and Wong WS: Targeting mitogen-activated protein kinases for asthma. Curr Drug Targets 7: 691-698, 2006.

30. Talati M, Meyrick B, Peebles RS Jr, Davies SS, Dworski R, Mernaugh R, Mitchell D, Boothby M, Roberts LJ II, Sheller JR: Oxidant stress modulates murine allergic airway responses. Free Radic Biol Med 40: 1210-1219, 2006.

31. Cohn L, Elias JA and Chupp GL: Asthma: Mechanisms of disease persistence and progression. Annu Rev Immunol 22: 789-815, 2004

32. Cameron EJ, McSharry C, Chaudhuri R, Farrow S, Thomson NC: Long-term macrolide treatment of chronic inflammatory airway diseases: Risks, benefits and future developments. Clin Exp Allergy 42: 1302-1312, 2012

33. Zhang Y, Lamm WJ, Albert RK, Chi EY, Henderson WR Jr and Lewis DB: Influence of the route of allergen administration and genetic background on the murine allergic pulmonary response. Am J Respir Crit Care Med 155: 661-669, 1997.

34. Wills-Karp M: Interleukin-13 in asthma pathogenesis. Immunol Rev 202: 175-190, 2004.

35. Cho JY, Miller M, Baek KJ, Han JW, Nayar J, Lee SY, McElwain K, McElwain S, Friedman S and Broide DH: Inhibition of airway remodeling in IL-5-deficient mice. J Clin Invest 113: 551-560, 2004

36. Huber AR, Kunkel SL, Todd RF III and Weiss SJ: Regulation of transendothelial neutrophil migration by endogenous interleukin-8. Science 254: 99-102, 1991

37. Jatakanon A, Uasuf C, Maziak W, Lim S, Chung KF and Barnes PJ: Neutrophilic inflammation in severe persistent asthma. Am J Respir Crit Care Med 160: 1532-1539, 1999.

38. Lukacs NW, Miller AL and Hogaboam CM: Chemokine receptors in asthma: Searching for the correct immune targets. J Immunol 171: 11-15, 2003.

39. ten Hove W, Houben LA, Raaijmakers JAM, Bracke M and Koenderman L: Differential regulation of TNF and GM-CSF induced activation of P38 MAPK in neutrophils and eosinophils. Molecular Immunology 44: 2492-2496, 2007.

40. Fujiwara N and Kobayashi K: Macrophages in inflammation. Curr. Drug Targets Inflamm. Allergy 4: 281-286, 2005.

41. Lee $T$ and Sousa A: Immunoinflammatory role of the airway epithelial cell in asthma. Eur Respir Rev 4: 368-370, 1994.

42. Kampen GT, Stafford S, Adachi T, Jinquan T, Quan S, Grant JA, Skov PS, Poulsen LK and Alam R: Eotaxin induces degranulation and chemotaxis of eosinophils through the activation of ERK2 and p38 mitogen-activated protein kinases. Blood 95: 1911-1917, 2000

43. Carl VS, Brown-Steinke K, Nicklin MJH and Smith MFS Jr: Toll-like receptor 2 and 4 (TLR2 and TLR4) agonists differentially regulate secretory interleukin-1 receptor antagonist gene expression in macrophages. J Biol Chem 277: 17448-17456, 2002.

44. Moon EY, Kang JS, Han SH, Yang KH, Pyo S, Lee MY, Lee HK and Yu DY: Differential role of peroxiredoxin II (PrxII) on the expression of toll-like receptor 4 (TLR4) and B-cell activating factor (BAFF) in ovalbumin (OVA)-induced mouse asthma. Int Immunopharmacol 8: 935-944, 2008.

45. Arbabi S and Maier RV: Mitogen-activated protein kinases. Crit Care Med 30 (Suppl): S74-S79, 2002. 